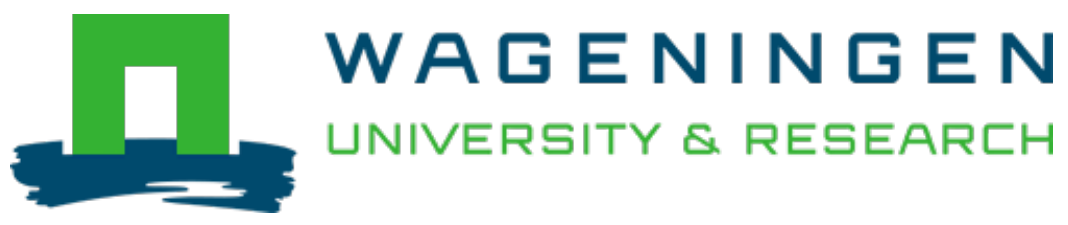

\title{
Determination of spray drift and buffer zones in 3D crops using the ISO standard and new LiDAR methodologies
}

\author{
Science of the Total Environment \\ Torrent, Xavier; Gregorio, Eduard; Rosell-Polo, Joan R.; Arnó, Jaume; Peris, Miquel et al \\ https://doi.org/10.1016/j.scitotenv.2020.136666
}

This publication is made publicly available in the institutional repository of Wageningen University and Research, under the terms of article $25 \mathrm{fa}$ of the Dutch Copyright Act, also known as the Amendment Taverne. This has been done with explicit consent by the author.

Article 25 fa states that the author of a short scientific work funded either wholly or partially by Dutch public funds is entitled to make that work publicly available for no consideration following a reasonable period of time after the work was first published, provided that clear reference is made to the source of the first publication of the work.

This publication is distributed under The Association of Universities in the Netherlands (VSNU) 'Article $25 \mathrm{fa}$ implementation' project. In this project research outputs of researchers employed by Dutch Universities that comply with the legal requirements of Article $25 \mathrm{fa}$ of the Dutch Copyright Act are distributed online and free of cost or other barriers in institutional repositories. Research outputs are distributed six months after their first online publication in the original published version and with proper attribution to the source of the original publication.

You are permitted to download and use the publication for personal purposes. All rights remain with the author(s) and / or copyright owner(s) of this work. Any use of the publication or parts of it other than authorised under article $25 \mathrm{fa}$ of the Dutch Copyright act is prohibited. Wageningen University \& Research and the author(s) of this publication shall not be held responsible or liable for any damages resulting from your (re)use of this publication.

For questions regarding the public availability of this publication please contact openscience.library@wur.nl 


\title{
Determination of spray drift and buffer zones in 3D crops using the ISO standard and new LiDAR methodologies
}

\author{
Xavier Torrent ${ }^{\mathrm{a}, *}$, Eduard Gregorio ${ }^{\mathrm{a}}$, Joan R. Rosell-Polo ${ }^{\mathrm{a}}$, Jaume Arnó ${ }^{\mathrm{a}}$, Miquel Peris ${ }^{\mathrm{b}}$, \\ Jan C. van de Zande ${ }^{\mathrm{c}}$, Santiago Planas ${ }^{\mathrm{a}, \mathrm{d}}$ \\ a Research Group in AgroICT \& Precision Agriculture, Department of Agricultural and Forest Engineering, Universitat de Lleida (UdL)-Agrotecnio Center, Lleida, Spain \\ b Institut de Recerca i Tecnologia Agroalimentària (IRTA), Parc Científic i Tecnològic Agroalimentari, Lleida, Spain \\ ${ }^{c}$ Wageningen University \&'Research - Agrosystems Research, Wageningen, the Netherlands \\ ${ }^{\mathrm{d}}$ Plant Health Services, Generalitat de Catalunya, Lleida, Spain
}

\section{H I G H L I G H T S}

- The airborne and sedimenting drift was evaluated in 3D crops using ISO 22866.

- DRN proved to be an effective drift reduction technique in the tested 3D crops.

- A preliminary 3D crops spray drift model was developed for the EU Southern Zone.

- A LiDAR-based method for field assessment of spray drift was proposed.
G R A P H I C A L A B S T R A C T

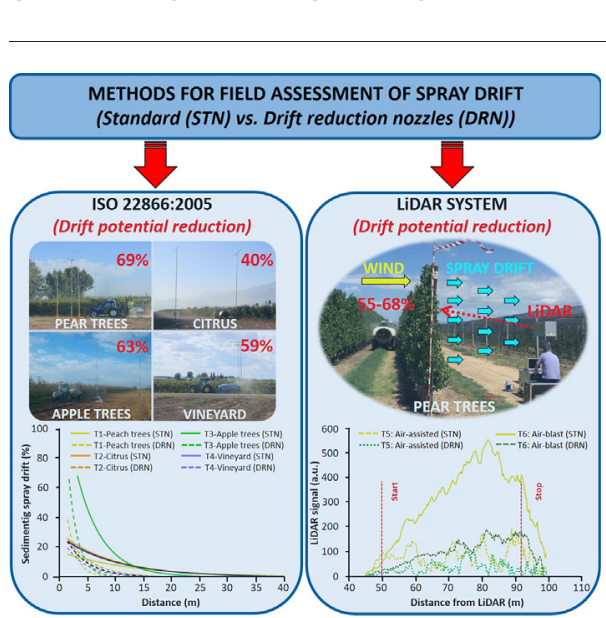

\section{A R T I C L E I N F O}

\section{Article history:}

Received 17 December 2019

Received in revised form 10 January 2020

Accepted 11 January 2020

Available online 15 January 2020

Editor: Damia Barcelo

\section{Keywords:}

Pesticide spraying

Spray drift

Light detection and ranging

Spray drift potential reduction

Hollow-cone nozzles

Remote sensing

\footnotetext{
* Corresponding author.

E-mail address: xavier.torrent@eagrof.udl.cat (X. Torrent).
} 


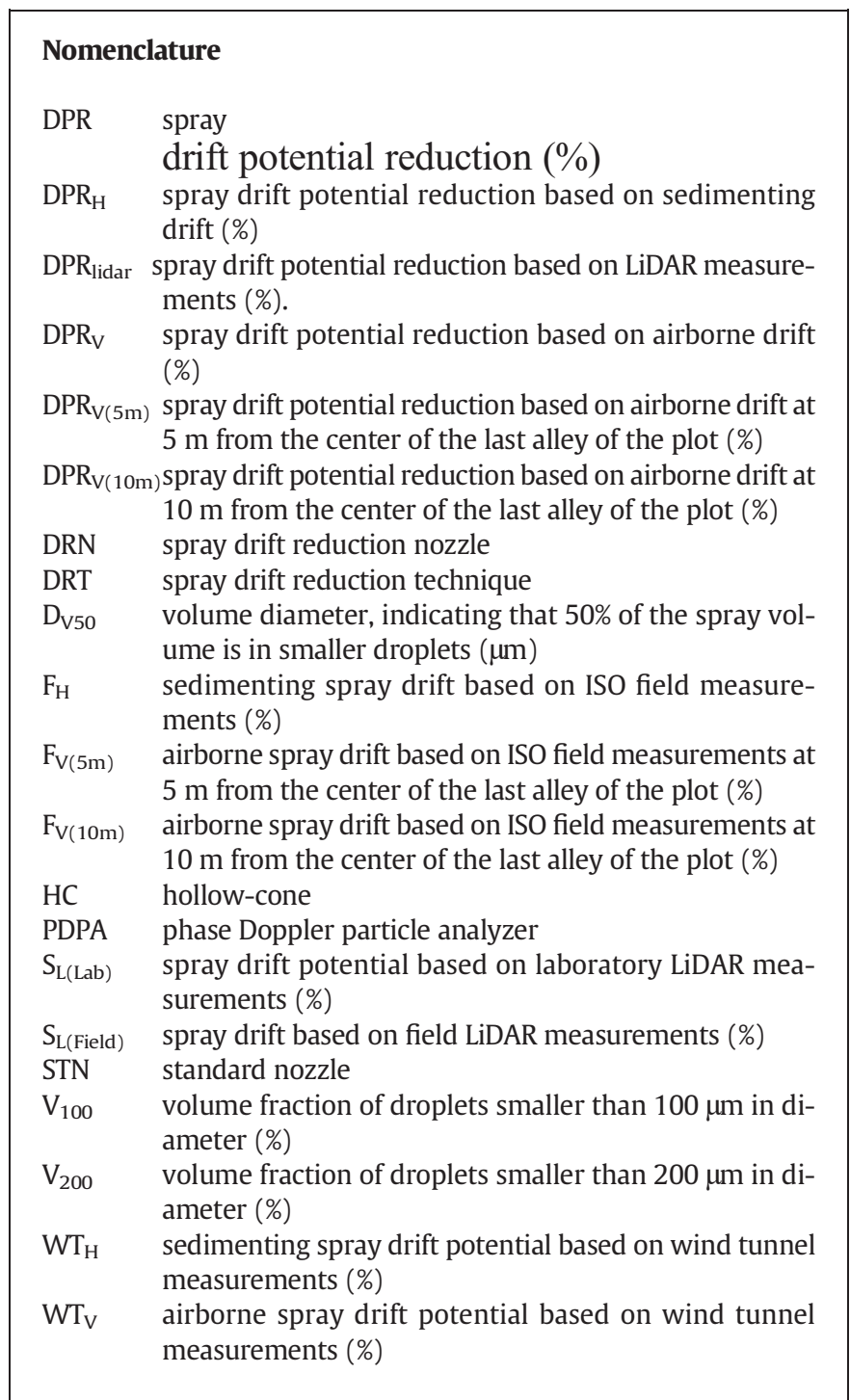

zone width in the countries of the EU Southern Zone depending on different environmental threshold values. Tests carried out using LiDAR system demonstrated high capacity and efficiency of this system and this newly defined methodology, allowing sprayer and nozzle types in real field conditions to be differentiated and classified. (c) 2020 Elsevier B.V. All rights reserved.

\section{Introduction}

The application of plant protection products (PPP) in crops is fundamental for the control of pests and diseases and to ensure agricultural production. According to Eurostat (2016), Spain was the EU country with the highest consumption of PPP (77 thousand tons), representing $20.9 \%$ of total EU consumption, followed by France ( 72 thousand tons; $19.5 \%$ ) and Italy (60 thousand tons; $16.3 \%$ ). In this scenario, spray drift associated with PPP spraying operations is a primary source of contamination. This phenomenon implies a clear risk for the health of bystanders and local residents (dermal exposure and inhalation) and for the environment (air, surface water, ground water, soil, fauna, flora and other crops) (Damalas, 2015; EPA, 2018; EPPO, 2003). These risks have been explored by several authors. Studies by Butler Ellis et al. $(2010,2018)$ on the exposure of bystanders to PPP airborne spray drift was used for the assessment of relevant UK regulations. Sjerps et al. (2019) analyzed drinking water sources in the Netherlands, identifying the presence of 15 pesticides. De Schampheleire et al (2007) evaluated spray drift damage to crops in Belgium, concluding that the most extreme risk situations occur in the case of 3D crops (fruit crops). In this regard, Sarigiannis et al. (2013) reported how most pesticide emissions generated in 3D crops are concentrated in Spain and Italy and that there are major differences between the countries of the EU Southern Zone and those of the Northern Zone as a result of climatic conditions.

One of the most important reasons for quantifying spray drift in 3D crops is to measure its potential reduction through the use of different spray drift reduction techniques (DRT): nozzle type (Derksen et al., 2007), sprayer type (Wenneker et al., 2016), air assistance (Duga et al., 2017), tractor-sprayer forward speed (Lešnik et al., 2015), windbreaks, buffer zones, etc. In this line, the European Directive 2009/128/ EC (EU, 2009) for sustainable pesticide use proposes the establishment of buffer zones as a drift reducing measure additional to the DRT. Buffer zones are defined as areas of land that allow the treatment area to be 
separated from non-target areas in order to mitigate the pollution caused by PPP treatments (Muscutt et al., 1993). In a recent study by Castro-Tanzi et al. (2018), the buffer distances were estimated according to the environmental risk of spray drift. Several studies have been carried out in the north of Europe to determine buffer zones in 2D (field crops) and 3D crops (De Schampheleire et al., 2007; van de Zande et al., 2010). However, as far as the authors of the present study are aware, no studies have been conducted to date on adaptation and adjustment of these buffer zones to the crop architecture and environmental conditions typical of the EU Southern Zone.

Spray drift in 3D crops is mainly influenced by the crop to be treated (canopy architecture and porosity, growth stage, etc.) (Da Silva et al., 2006; Kasner et al., 2018), sprayer design (fan characteristics, deflectors, etc.) (Blanco et al., 2019; Salyani et al., 2013), spray mix properties (surface tension, viscosity, etc.) (Stainier et al., 2006), operating conditions (droplet size distribution, liquid volume rate, forward speed, air assistance, etc.) (Nuyttens et al., 2005), and weather conditions (temperature, relative humidity, wind speed and direction, etc.) (Gil et al., 2007). It should be noted that most of the many numerous authors who have conducted spray drift tests in field conditions have only done so in 2D crops (Carlsen et al., 2006; Nuyttens et al., 2010; Wolters et al., 2008). As for the evaluation of spray drift in 3D crops, most of the few studies that have been carried out have focused on citrus (Cunha et al., 2012; Garcerá et al., 2017; Salyani et al., 2013). Recently, Bourodimos et al. (2019) has developed a new spray drift risk assessment tool (model) for vineyard that has been contrasted with ISO 22866:2005. It should also be noted that carrying out the tests in different scenarios (training system and architecture of crops, meteorological conditions, etc.) can lead to under or overestimations of spray drift, as was demonstrated by Ramos et al. (2000). Spray drift prediction models have been created from numerous tests conducted for spray drift evaluation. The best known in Europe are the German models for 2D and 3D crops based on 50 trials in field crops and 72 in fruit orchard (Ganzelmeier et al., 1995; Rautmann et al., 2001), and the Dutch model for pome fruit trees (apple and pear) based on 20 years of experimental data (Holterman et al., 2017).

Currently, the reference method for the evaluation of spray drift in real field conditions is ISO 22866:2005. However, conducting field spray drift trials based on this standard is very time consuming and laborious. An alternative methodology has been proposed for quantifying spray drift based on LiDAR technology (Gregorio et al., 2014, 2019; Hiscox et al., 2006; Richardson et al., 2017), due to its advantages in terms of measurement capacity (temporal and spatial resolution, real time measurements), as well as its reduced labour and time requirements. Other authors as Gil et al. (2013) have tested low-cost LiDAR sensors obtaining spray drift measurements that were not range- resolved. Another optical remote sensing technique used to evaluate the spray drift is the Open-Path Fourier Transform Infra-Red (OP-FTIR) spectrometry (Kira et al., 2018).

Given all of the above, there is a clear need to know the effect and behavior of spray drift in all the main 3D crops in the EU Southern Zone and to adopt appropriate and effective DRT. Consequently, the first aim of this work is to evaluate spray drift (sedimenting and airborne) for different types of standard (STN) and spray drift reduction nozzles (DRN) in different 3D crops (peach, apple, citrus, grape) in field conditions, using ISO 22866:2005 (2005). The second aim is to determine and compare the buffer zones required to minimize the effects of spray drift in the different crop and nozzle types studied. The third aim of this work is to define and perform a preliminary validation of a new methodology to measure spray drift in real field conditions using an ad hoc LiDAR system.

\section{Materials and methods}

\subsection{Sprayer and nozzle characterization}

Seven field spray drift tests (T1-T7) were conducted in compliance with ISO 22866:2005 in which STN and DRN hollow-cone nozzles were compared in four 3D crops (peach, citrus, apple and grape). Table 1 shows the characteristics of the orchards and crops, and Table 2 specifies the sprayers and nozzles used in each test and their operating conditions.

The sprayer used in the first test (T1) was a cross-flow air-assisted sprayer (Arrow F-1000, Hardi S.A., Lleida, Spain) with an air flow rate of $65,000 \mathrm{~m}^{3} \cdot \mathrm{h}^{-1}$ and equipped with 20 operating nozzles. The nozzles were standard hollow-cone Albuz ATR 80 Orange (STN-O) (Solcera, Evreux, France) and spray drift reduction hollow-cone Albuz TVI 8002 Yellow (DRN-Y), operating at 1.0 and $0.9 \mathrm{MPa}$, respectively, with flow rates of $1.39 \mathrm{~L} \cdot \mathrm{min}^{-1}$ in both cases. The T1 test was carried out in a commercial 'Big Top' peach orchard (Prunus persica (L.) Batsch) with trees trained in an open vase system and located in the IRTA Experimental Station in Gimenells (Lleida, Spain) (latitude: 282807.00 E, longitude: $4614876.00 \mathrm{~N}$ ).

In the second test (T2), an axial fan air-blast sprayer (Twister 2000, Mañez and Lozano S.L., Valencia, Spain) was used, with a measured air flow rate of $29.700 \mathrm{~m}^{3} \cdot \mathrm{h}^{-1}$ and equipped with 20 operating nozzles. In this case, the nozzles used were ATR 80 Grey (STN-G1) at $1.5 \mathrm{MPa}$ and TVI 8003 Blue (DRN-B1) at $1.3 \mathrm{MPa}$, operating with flow rates of 2.51 and $2.50 \mathrm{~L} \cdot \mathrm{min}^{-1}$, respectively. In this case, the test was performed in globular-trained citrus trees, in a commercial 'Clementine' citrus orchard (Citrus clementine) located in Roquetes (Tarragona, Spain) (latitude: $286047.00 \mathrm{E}$, longitude: $4517792.00 \mathrm{~N}$ ).

Table 1

Characteristics of the orchards where the tests were carried out.

\begin{tabular}{|c|c|c|c|c|c|c|}
\hline \multirow{2}{*}{\multicolumn{2}{|c|}{ Parameters }} & \multicolumn{5}{|c|}{ 3D crops } \\
\hline & & Peach trees & Citrus trees & Apple trees & Vineyard & Pear trees \\
\hline & Test & T1 & $\mathrm{T} 2$ & T3 & T4 & T5, T6, T7 \\
\hline \multirow{5}{*}{ Orchard } & Cultivar & Big Top & Clementine & Golden & Chardonnay & Conference \\
\hline & Area (ha) & 0.64 & 6.67 & 1.64 & 0.52 & 0.73 \\
\hline & Row direction & $\mathrm{E}-\mathrm{W}\left(-35^{\circ}\right)$ & $\mathrm{E}-\mathrm{W}\left(18^{\circ}\right)$ & $\mathrm{E}-\mathrm{W}\left(-70^{\circ}\right)$ & $\mathrm{E}-\mathrm{W}\left(-83^{\circ}\right)$ & $\mathrm{E}-\mathrm{W}\left(-115^{\circ}\right)$ \\
\hline & Training system & Open vase & Globular & Hedgerow & Trellis & Hedgerow \\
\hline & $\begin{array}{l}\text { Tree spacing (between rows } \times \text { between trees) } \\
\qquad(\mathrm{m} \times \mathrm{m})\end{array}$ & $5.00 \times 2.00$ & $6.00 \times 4.00$ & $3.45 \times 0.60$ & $3.00 \times 1.80$ & $3.30 \times 1.00$ \\
\hline \multirow{6}{*}{ Canopy } & Height, $\mathrm{h}(\mathrm{m})$ & 2.90 & 2.85 & 2.80 & 1.25 & 3.00 \\
\hline & Width along row (m) & $2.70^{\mathrm{a}}$ & $2.80^{\mathrm{a}}$ & $1.20^{\mathrm{b}}$ & $2.00^{\mathrm{b}}$ & $2.00^{\mathrm{b}}$ \\
\hline & Width crossing row (m) & 2.95 & 2.50 & 1.90 & 0.86 & 0.50 \\
\hline & Growth stage $(\mathrm{BBCH})$ & $\begin{array}{c}91 \text { (Fruit growth, } \\
60 \% \text { ) }\end{array}$ & $\begin{array}{c}89 \text { (Fruit growth, } \\
95 \%)\end{array}$ & $\begin{array}{l}93 \text { (Beginning of leaf } \\
\text { fall) }\end{array}$ & $\begin{array}{l}91 \text { (Post- } \\
\text { harvest) }\end{array}$ & $\begin{array}{c}74 \text { (Fruit growth, } \\
40 \% \text { ) }\end{array}$ \\
\hline & $\operatorname{LWA}\left(\mathrm{m}^{2} \cdot \mathrm{ha}^{-1}\right)$ & 11,600 & 9,500 & 16,231 & 8,333 & 18,181 \\
\hline & LAI & 3.02 & 3.15 & 1.80 & 1.05 & 2.20 \\
\hline
\end{tabular}

a: Individual trees.

b: trees growing into each other in the row. 
Table 2

Description of the spray drift tests.

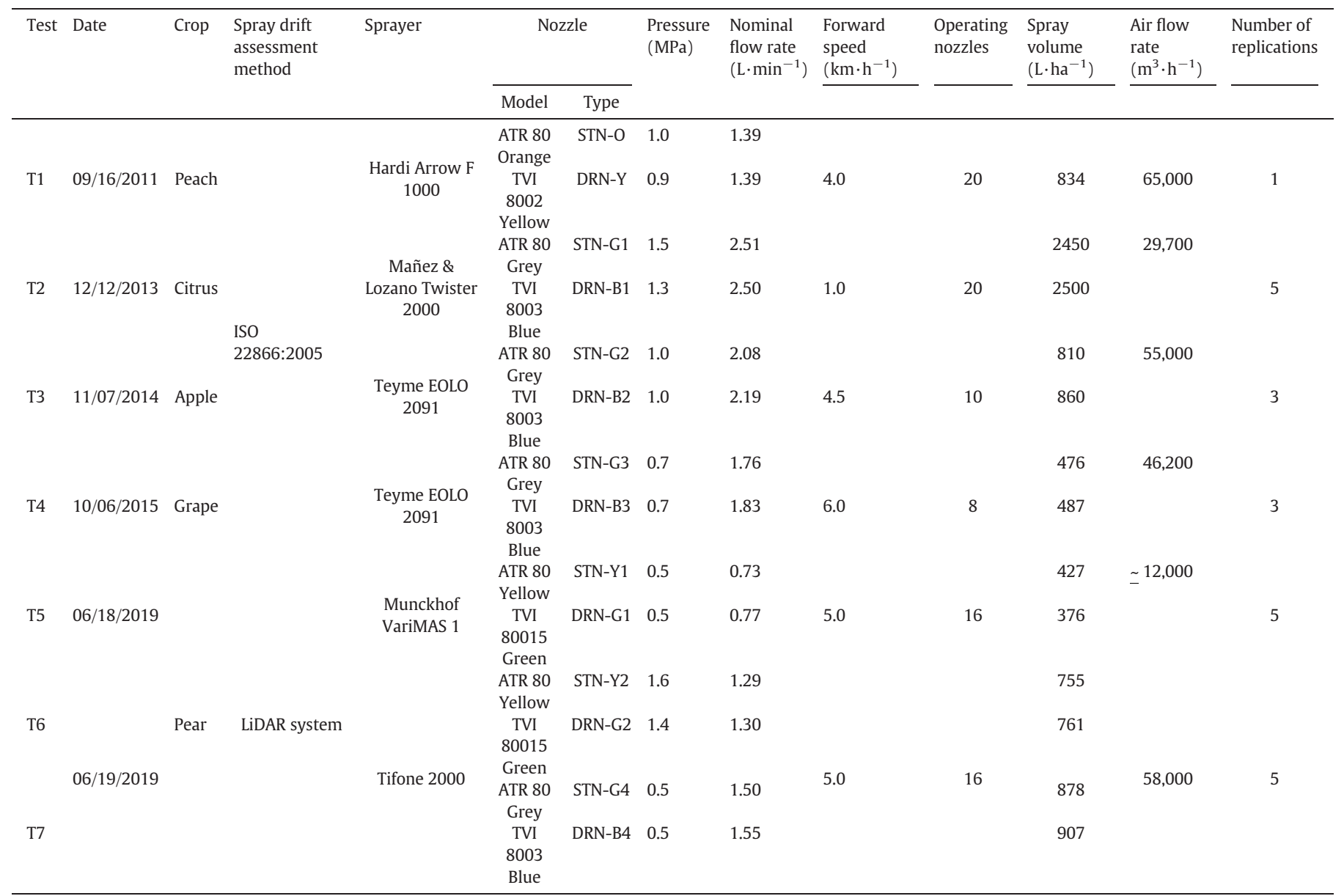

STN: Hollow-cone standard nozzle; DRN: Hollow-cone spray drift reduction nozzle.

In the third and fourth tests (T3 and T4), the sprayer was a conventional axial fan air-blast with deflectors in the upper and bottom part of the arc of the nozzles (Eolo 2091, Teyme Tecnología Agrícola S.L., TorreSerona, Spain). In test T3, the 10 available nozzles of the sprayer were used and the air flow rate was $55,000 \mathrm{~m}^{3} \cdot \mathrm{h}^{-1}$, while in test T4 only 8 nozzles were used and the air flow rate was set at $46,200 \mathrm{~m}^{3} \cdot \mathrm{h}^{-1}$. In test T3, the nozzles that were compared were the standard hollowcone nozzle ATR 80 Grey at 1.0 MPa (STN-G2) and the spray drift reduction hollow-cone nozzle TVI 8003 Blue at 1.0 MPa (DRN-B2), with flow rates of 2.08 and $2.19 \mathrm{~L} \cdot \mathrm{min}^{-1}$, respectively. In the T4 test, the same ATR 80 Grey (STN-G3) and TVI 8003 Blue (DRN-B3) nozzles were used, although the working pressure in this case was $0.7 \mathrm{MPa}$ for both, and their respective flow rates were 1.76 and $1.83 \mathrm{~L} \cdot \mathrm{min}^{-1}$.

The T3 test was performed with hedgerow-trained 'Golden' apple trees (Malus domestica) in an orchard located in the IRTA Experimental Station at Gimenells (Lleida, Spain) (latitude: 282765.00 E, longitude: $4615309.00 \mathrm{~N}$ ). The commercial plot where the T4 test was carried out corresponded to a 'Chardonnay' vineyard (Vitis vinífera) which employed a trellis training system, located in Raimat (Lleida, Spain) (latitude: $289105.00 \mathrm{E}$, longitude: $4616616.39 \mathrm{~N}$ ).

In the fifth test (T5), an air-assisted orchard sprayer (VariMAS 1, Munckhof Fruit Tech Innovators, A.J. Horst, The Netherlands) with an air flow rate of $11,700 \mathrm{~m}^{3} \cdot \mathrm{h}^{-1}$ and equipped with 16 operating nozzles was used. This sprayer, which is innovative in the area where the tests were carried out, achieves an optimal leaf coverage and a high spray drift reduction. The nozzles used were ATR 80 Yellow at $0.5 \mathrm{MPa}$ (STN-Y) and TVI 80015 Green at $0.5 \mathrm{MPa}$ (DRN-G) with flow rates of 0.73 and $0.77 \mathrm{~L} \cdot \mathrm{min}^{-1}$, respectively.
For the sixth and seventh tests (T6 and T7), the spraying equipment used was a conventional axial fan air-blast sprayer (model 2000, Tifone, Cassana, Italy) with an air flow rate of $58,000 \mathrm{~m}^{3} \cdot \mathrm{h}^{-1}$ and equipped with 16 operating nozzles. Two pairs of STN and DRN nozzles were compared using this equipment. In the T6 test, ATR 80 Yellow at $1.6 \mathrm{MPa}$ (STN-Y2) and TVI 80015 Green at 1.4 MPa (DRN-G2) nozzles were used, with flow rates of $1.29 \mathrm{~L} \cdot \mathrm{min}^{-1}$ and $1.30 \mathrm{~L} \cdot \mathrm{min}^{-1}$, respectively. In the T7 test, ATR 80 Grey at $0.5 \mathrm{MPa}$ (STN-G4) and TVI 8003 Blue also at $0.5 \mathrm{MPa}$ (DRN-B4) nozzles were used, with flow rates of 1.50 and $1.55 \mathrm{~L} \cdot \mathrm{min}^{-1}$, respectively.

The T5, T6 and T7 tests were conducted in a commercial 'Conference' pear orchard (Pyrus communis) with a hedgerow training system, located in the IRTA Experimental Station in Mollerussa (Lleida, Spain) (latitude: $322596.05 \mathrm{E}$, longitude: $4609495.68 \mathrm{~N}$ ).

Table 1 shows the leaf wall area (LWA) and the leaf area index (LAI) values for the testing orchards. The LWA was calculated taking into account the canopy height and the tree spacing between rows, and the LAI, expressed as leaf area per individual tree ground surface area, was calculated for each crop using the method developed by Sanz et al. (2018).

\subsection{Meteorological conditions}

During the development of each test detailed in Section 2.1, the meteorological conditions corresponding to temperature, relative humidity, wind speed and direction were recorded with an acquisition frequency of $1 \mathrm{~Hz}$. In the T1 test, a combined temperature and relative humidity sensor (HMP45 C and Pt 100, Vaisala Inc., Vaanta, Finland), 
Table 3

Meteorological conditions during the tests. The average values of temperature, relative humidity, wind speed and wind direction are shown.

\begin{tabular}{|c|c|c|c|c|c|c|c|}
\hline Test & Nozzle & $\mathrm{T}\left({ }^{\circ} \mathrm{C}\right)$ & $\mathrm{RH}(\%)$ & Wind speed $\left(\mathrm{m} \cdot \mathrm{s}^{-1}\right)$ & Wind direction ${ }^{1}\left({ }^{\circ}\right)$ & Wind speed measurements $<1 \mathrm{~m} \cdot \mathrm{s}^{-1}$ & Wind direction measurements upper $\pm 45^{\circ}(\%)$ \\
\hline \multirow{2}{*}{$\mathrm{T} 1$} & STN-O & 20.7 & 57.8 & 1.2 & 8.3 & 8.2 & 6.5 \\
\hline & DRN-Y & 21.3 & 57.0 & 1.4 & 6.9 & 7.6 & 4.1 \\
\hline \multirow{2}{*}{$\mathrm{T} 2$} & STN-G1 & 9.1 & 61.3 & 2.2 & -20.8 & & 1.9 \\
\hline & DRN-B1 & 9.4 & 61.2 & 1.9 & -20.4 & & 5.4 \\
\hline \multirow{2}{*}{ T3 } & STN-G2 & 16.4 & 53.5 & 1.8 & -14.2 & & 3.7 \\
\hline & DRN-B2 & 15.3 & 50.0 & 1.6 & -9.4 & & 2.5 \\
\hline \multirow{2}{*}{$\mathrm{T} 4$} & STN-G3 & 20.5 & 48.9 & 2.2 & -5.3 & & 9.6 \\
\hline & DRN-B3 & 21.2 & 48.2 & 2.6 & -3.8 & & 7.4 \\
\hline \multirow{2}{*}{ T5 } & STN-Y & 23.2 & 31.0 & 2.5 & -15.1 & 0.0 & 15.8 \\
\hline & DRN-G & 23.9 & 30.6 & 2.9 & -13.6 & & 12.1 \\
\hline \multirow{2}{*}{ T6 } & STN-Y & 21.3 & 41.1 & 2.2 & 16.3 & & 17.3 \\
\hline & DRN-G & 23.1 & 40.6 & 2.5 & 13.9 & & 15.2 \\
\hline \multirow{2}{*}{$\mathrm{T} 7$} & STN-G4 & 23.7 & 35.6 & 1.7 & 22.7 & & 19.1 \\
\hline & DRN-B4 & 24.4 & 35.1 & 2.2 & 19.4 & & 17.8 \\
\hline
\end{tabular}

${ }^{1}$ Wind direction respect to the perpendicular of tree rows.

and a wind speed and direction sensor (05103, RM Young, Traverse City, MI, USA) were used. All sensors were connected to a datalogger (CR510, Campbell Scientific Inc., Logan, UT, USA). In contrast, in tests T2, T3 and T4, a portable weather station equipped with temperature (model MCP9808, Adafruit Industries LLC, New York, NY, USA), humidity (model HIH 5030/5031, Honeywell, Golden Valley, MN, USA), wind speed (model Watson 8681-WSS, W\&S, Hockley, Essex, UK), and wind direction (ACE-128 encoder, Bourns, Riverside, CA, USA) sensors were used. Finally, in tests T5, T6 and T7, the weather conditions were recorded using a compact ultrasonic weather station (WXH220 model, Airmar Technology Corporation, Milford, NH, USA).
In tests T1-T4, all sensors were placed on a mast located $20 \mathrm{~m}$ away from the last row of trees. The temperature and relative humidity sensors were installed at $4 \mathrm{~m}$ high and the wind speed and direction sensors at $7 \mathrm{~m}$ high. In tests $\mathrm{T5}-\mathrm{T7}$, the weather station was located at the beginning of the last row of trees, at a height of $7 \mathrm{~m}$.

Table 3 shows the recorded meteorological data, indicating the average values for each of the tests. These measurements comply with the ranges established in ISO 22866:2005: wind speed between 1 and $3 \mathrm{~m} \cdot \mathrm{s}^{-1}$ with no $>10 \%$ of wind measurements lower than $1 \mathrm{~m} \cdot \mathrm{s}^{1}$, and wind direction in the range of $\pm 30^{\circ}$ to the perpendicular to the spray track with no $>30 \%$ of results upper $45^{\circ}$.
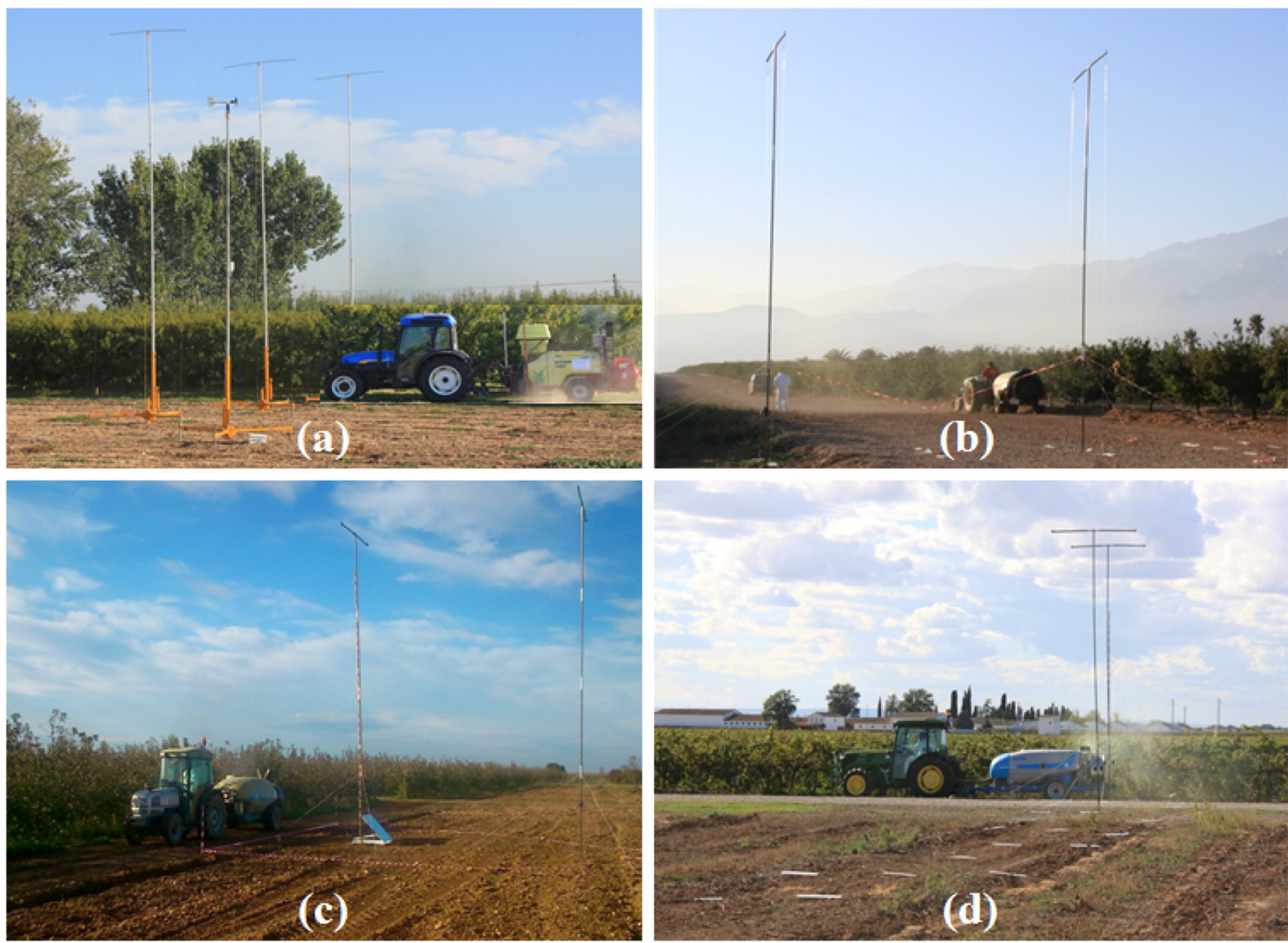

Fig. 1. Orchards tested for spray drift assessment with vertical and horizontal collectors: a) peach trees; b) citrus; c) apple trees; d) vineyard. 


\subsection{ISO 22866:2005 methodology}

In the T1, T2, T3 and T4 tests, detailed in Table 1, the ISO 22866:2005 based methodology was applied. Prior to the performance of all tests, the equipment was calibrated by adjusting the application volume to the tree structure and the foliar density of the canopy. To evaluate the airborne spray drift, $6 \mathrm{~m}$ long nylon string collectors were fixed vertically to two masts positioned, respectively, at $5 \mathrm{~m}$ and $10 \mathrm{~m}$ from the center of the last alley of the plot and perpendicular to it. Two collectors spaced $2 \mathrm{~m}$ apart were placed on each of the masts. To evaluate the sedimenting spray drift, terrestrial collectors were used, in this case $0.515 \times 0.065 \mathrm{~m}$ horizontal blotting paper collectors $\left(73 \mathrm{~g} \cdot \mathrm{m}^{-2}\right.$ filters, Anoia S.A., Barcelona, Spain). These were distributed in 3 columns separated $1.5 \mathrm{~m}$ from the center of each collector and positioned at the following perpendicular distances from the center of the last alley of the plot: $1.5,2.5,5.7 .5,10,12.5,15,17.5,20,25,30,35$ and $40 \mathrm{~m}$. The sprayed liquid was a mixture of tap water and brilliant sulfoflavine (BSF) tracer at $1 \mathrm{~g} \cdot \mathrm{L}^{-1}$. In order to know the concentration of the mixture in the tank, two samples were taken from a spray nozzle, one before application and the other after. In Torrent et al. (2017), a detailed description of the methodology applied is presented.

In test T1, carried out in peach trees, the STN-O and DRN-Y nozzles were contrasted, performing one repetition for each nozzle type. The forward speed was $4 \mathrm{~km} \cdot \mathrm{h}^{-1}$, applying a volume of $834 \mathrm{~L} \cdot \mathrm{ha}^{-1}$. The treatment area included a total of 4 alleys ( 3 alleys where both sides were sprayed and 2 half-alleys where spraying was only performed on the side of the vegetation), so the treated width was $20 \mathrm{~m}$.

The T2 test was performed in citrus using the STN-G1 and DRN-B1 nozzles, with a total of 5 repetitions for each nozzle type. The forward speed was $1.0 \mathrm{~km} \cdot \mathrm{h}^{-1}$, applying a volume of $2450 \mathrm{~L} \cdot \mathrm{ha}^{-1}$ with the STN-G1 and $2500 \mathrm{~L} \cdot \mathrm{ha}^{-1}$ with the DRN-B1. The treated area also consisted of 4 alleys, being the treated width of $24 \mathrm{~m}$.

In the T3 test, conducted on apple trees, the application was carried out with the STN-G2 and DRN-B2 nozzles, with a total of 3 repetitions for both nozzle types. The forward speed was $4.5 \mathrm{~km} \cdot \mathrm{h}^{-1}$ and the application volume was $810 \mathrm{~L} \cdot \mathrm{ha}^{-1}$ for the STN-G2 nozzles and $860 \mathrm{~L} \cdot \mathrm{ha}^{-1}$ for the DRNB2 nozzles. The treated width was $24 \mathrm{~m}$, corresponding to 7 alleys.
Finally, in the T4 test conducted in a vineyard, the nozzles used were the STN-G3 and the DRN-B3, with 3 repetitions in both cases. The forward speed was $6.0 \mathrm{~km} \cdot \mathrm{h}^{-1}$, and the applied volume $476 \mathrm{~L} \cdot \mathrm{ha}^{-1}$ for the STN-G3 and $487 \mathrm{~L} \cdot \mathrm{ha}^{-1}$ for the DRN-B3. In this case, the treated area consisted of 7 alleys with a treated width of $21 \mathrm{~m}$.

The arrangement of the vertical masts for the detection of aerial spray drift in the four plots on which spray drift was evaluated is shown in Fig. 1.

\subsection{LiDAR methodology}

In tests T5, T6 and T7, spray drift under field conditions was evaluated using an ad hoc LiDAR system developed by Gregorio et al. (2015, 2016). This instrument has a laser emitter (Er-glass laser) with a wavelength of $1534 \mathrm{~nm}$, which emits pulses of $3 \mathrm{~mJ}$ energy and $6 \mathrm{~ns}$ duration. The backscattered light is captured by a telescope with $80 \mathrm{~mm}$ aperture, and, through a set of optics, is focused on the photodetector surface of an avalanche photodiode (APD) module that converts the light signal received into an electrical signal. As shown in Fig. 2, the emission and receiving subsystems have a pan \& tilt unit, which allows azimuth and elevation scanning. This LiDAR system is eye safe and has a spatial resolution of $2.4 \mathrm{~m}$.

The tests T5, T6 and T7 were carried out in pear trees, performing the treatment only along the second path, spraying at both sides, with a forward speed of $5 \mathrm{~km} \cdot \mathrm{h}^{-1}$. In the T5 test, the STN-Y1 $\left(427 \mathrm{~L} \cdot \mathrm{ha}^{-1}\right)$ and DRN-G1 (376 L $\cdot \mathrm{ha}^{-1}$ ) nozzles were compared; in the T6 test, the STN-Y2 (755 L $\left.\cdot \mathrm{ha}^{-1}\right)$ and the DRN-G2 $\left(761 \mathrm{~L} \cdot \mathrm{ha}^{-1}\right)$; and in the T7 test, the nozzles compared were the STN-G4 $\left(878 \mathrm{~L} \cdot \mathrm{ha}^{-1}\right)$ and DRNB4 $\left(907 \mathrm{~L} \cdot \mathrm{ha}^{-1}\right)$. A total of 5 repetitions were carried out with each of the aforementioned nozzles.

As shown in Fig. 3a, the LiDAR system was placed parallel to the last row of trees at a distance of $3.3 \mathrm{~m}$ from it, equivalent to the width of one of the alleys of that plot. The height of the emitter and receiver system with respect to the ground was $0.8 \mathrm{~m}$. This height was determined to avoid the ground irregularities and the impact of the laser beam to the ground.

In Fig. 3b the type of measurement is presented, consisting of scans in the vertical plane, with a scanning angle of $4.5^{\circ}$. This angle was set

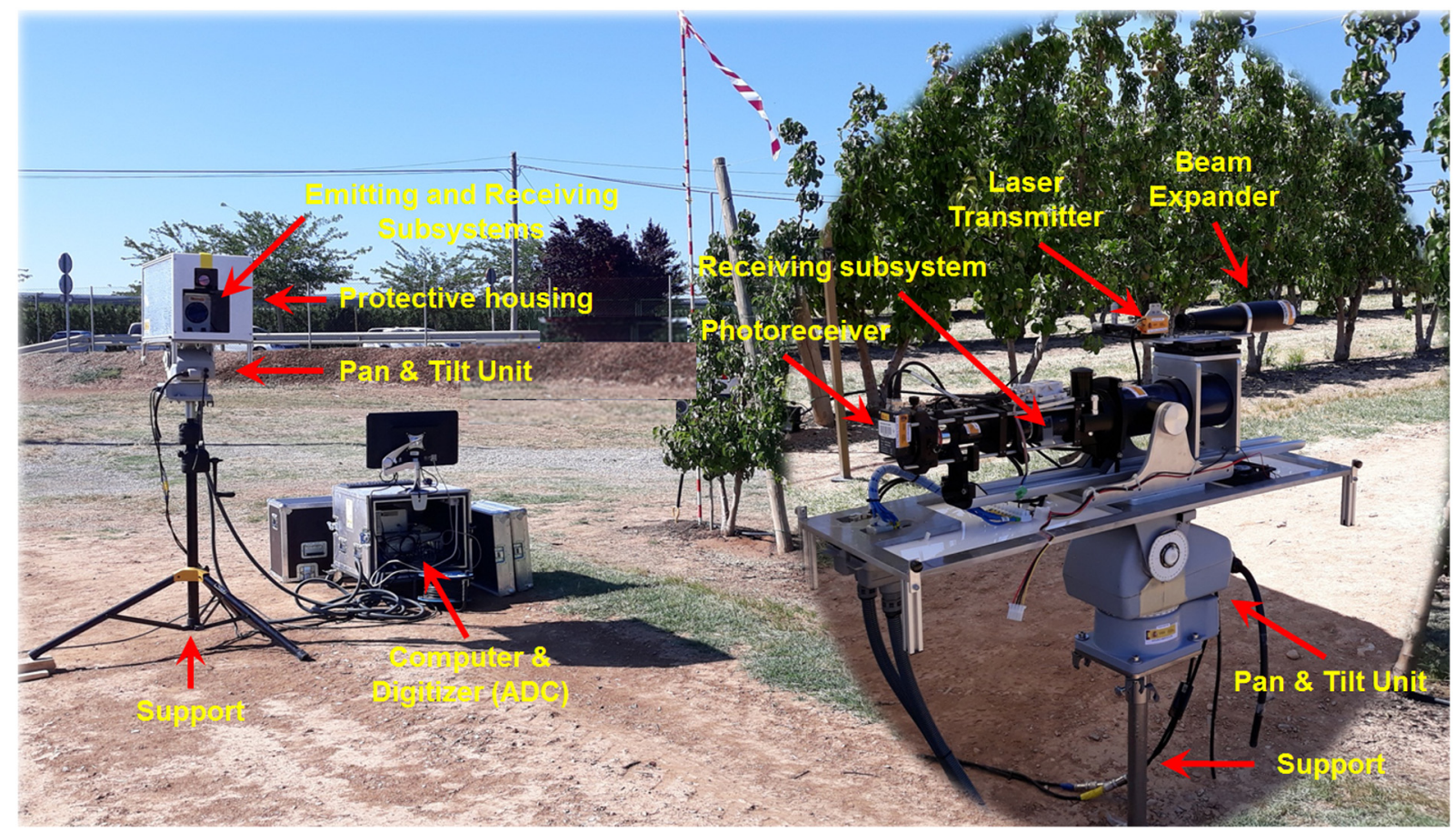

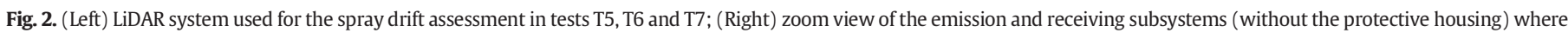
internal optoelectronic components are shown. 


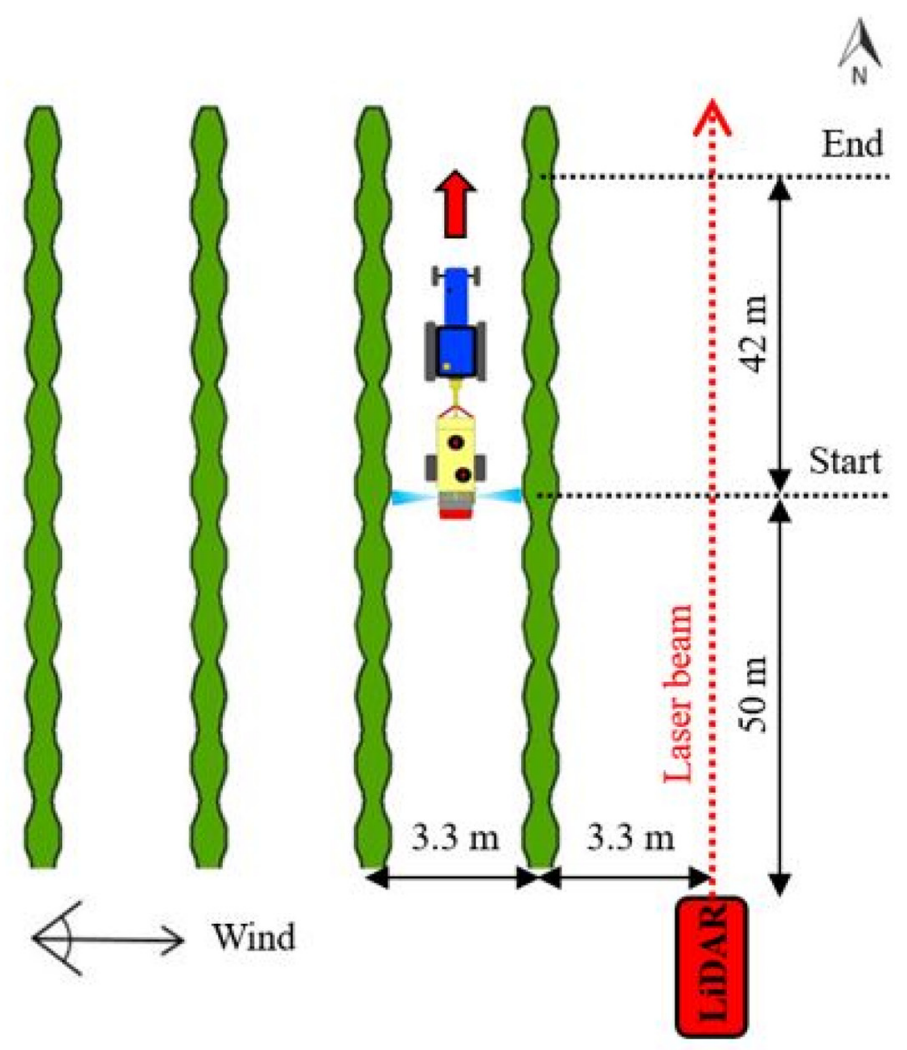

(a)

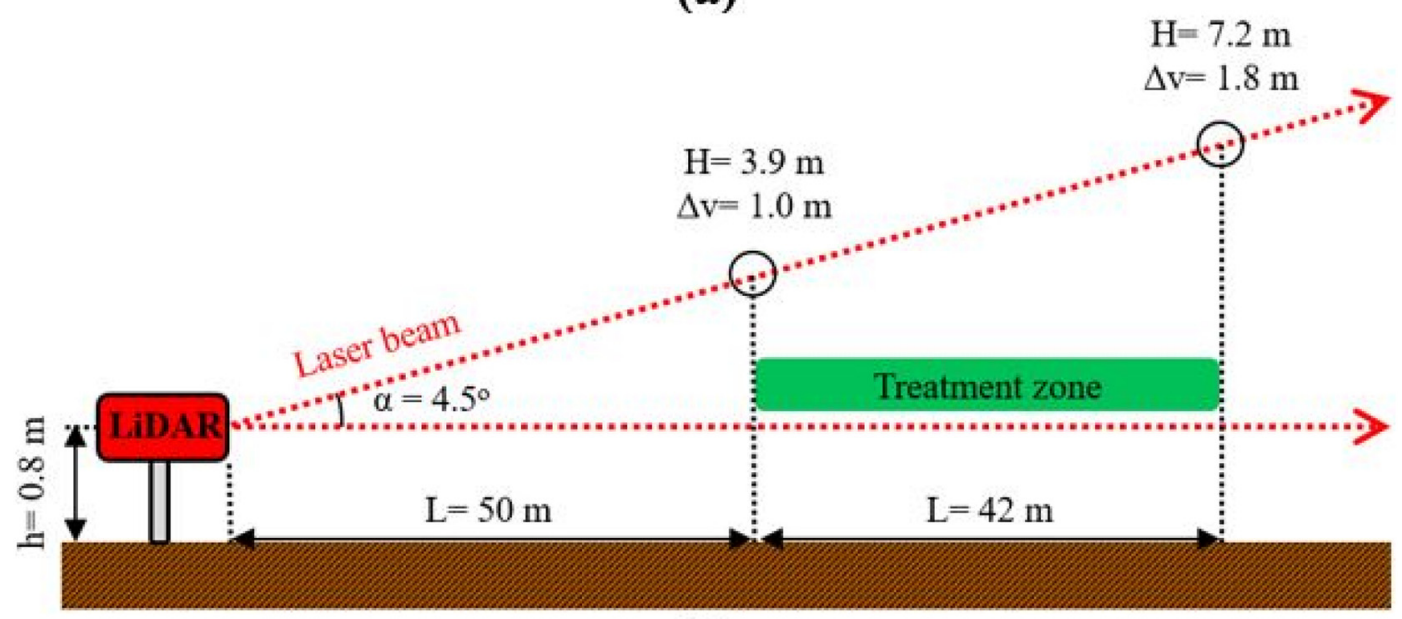

(b)

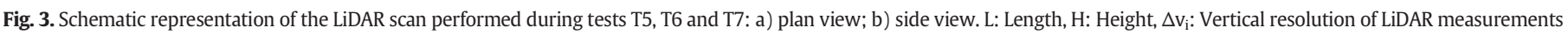
considering a pulse repetition rate of $1 \mathrm{~Hz}$.

so that the scan collected the entire spray drift cloud, starting at a minimum height of $3.9 \mathrm{~m}$ and a vertical resolution of $1.0 \mathrm{~m}$ at the beginning of the treatment area, until reaching $7.2 \mathrm{~m}$ in height and a vertical resolution of $1.8 \mathrm{~m}$ at the end of this area. The angular velocity was $1.13^{\circ} / \mathrm{s}$ and the pulse rate frequency $1 \mathrm{~Hz}$. The objective with this methodology was to evaluate the spray drift cloud that passed through a window parallel to the last row of trees. In this way, parameters such as sweep angle, angular velocity and pulse rate frequency allow adjustment of the spatial and temporal resolution of LiDAR measurements.

Spraying started at $50 \mathrm{~m}$ from the LiDAR system and ended at $92 \mathrm{~m}$, so the sprayed length was $42 \mathrm{~m}$. The following measurement sequence was followed: Start of the LiDAR measurement (laser emission) ( $T=$ $0 \mathrm{~s})$; Spray start $(T=30 \mathrm{~s})$; End of spraying and stopping the tractor $(T=60 \mathrm{~s})$; End of the LiDAR measurement $(T=100 \mathrm{~s})$.
During the first $30 \mathrm{~s}$ (before starting the spraying), measurements of the background signal, necessary for post-processing, were made. In addition, it should be noted that, before each spray drift test, tests were performed for the presence of dust generated by the motion of the tractorsprayer equipment and by the fan itself. If dust was detected, the ground was wetted to avoid significant distortion of the background signal.

\subsection{Data analysis}

\subsubsection{ISO spray drift tests}

2.5.1.1. Experimental design analysis. Two linear models were formulated for each of the crops tested as proposed by Garcerá et al. (2017) in similar PPP studies. In the first model (airborne spray drift deposition), an 
analysis of variance (ANOVA) for a three-way factorial treatment structure was adopted. The analysis of vertical deposits (dependent variable in the model) allowed significant effects of fixed factors such as nozzle type $(\alpha)$, distance to the tree row $(\beta)$, and collector height $(\gamma)$ to be assessed. Other factors such as crop type, air assistance capacity and wind speed were only considered at qualitative level. So, the proposed model was as follows,

$y_{i j k l}=\mu+\alpha_{i}+\beta_{j}+\gamma_{k}+\alpha \beta_{i j}+\alpha \gamma_{i k}+\beta \gamma_{j k}+\alpha \beta \gamma_{i j k}+e_{i j k l}$

where $i=1,2 ; j=1,2 ; k=1 \ldots 6$, with $y_{i j k l}$ the vertical deposit value $l$ obtained at height $k(1,2,3,4,5$ or $6 \mathrm{~m})$ and distance $j(5$ or $10 \mathrm{~m})$ for nozzle $i$ (STN or DRN); $\mu$ is the general average; $\alpha_{i}$ the effect of level $i$ of the fixed factor $A$ (nozzle type); $\beta_{j}$ the effect of level $j$ of the fixed factor B (distance); $\gamma_{k}$ the effect of level $k$ of the fixed factor C (collector height); $\alpha \beta_{i j} ; \alpha \gamma_{i k} ; \beta \gamma_{j k} ; \alpha \beta \gamma_{i j k}$ the effects of the interactions between fixed factors $\mathrm{A}, \mathrm{B}$ and $\mathrm{C}$; and $e_{i j k l}$ is the error term.

The second model was simpler. Considering now the sedimenting spray drift deposition as dependent variable, significant effects of nozzle type and distance of spray drift detection were tested through a twoway factorial fixed model formulated as before, according to the following expression:

$y_{i j l}=\mu+\alpha_{i}+\beta_{j}+\alpha \beta_{i j}+e_{i j l}$

where $i=1,2 ; j=1 \ldots 13$, with $y_{i j l}$ the horizontal deposit value $l$ obtained at distance $j(1.5,2.5,5,7.5,10,12.5,15,17.5,20,25,30,35$ or $40 \mathrm{~m}$ ) for nozzle $i$ (STN or DRN); $\mu$ is the general average; $\alpha_{i}$ the effect of level $i$ of the fixed factor A (nozzle type); $\beta_{j}$ the effect of level $j$ of

\section{T1-PEACH TREES}

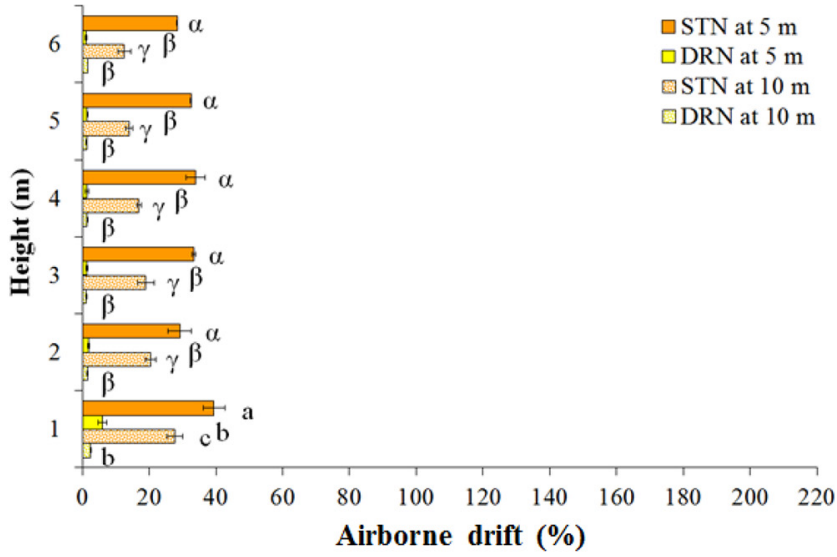

\section{T3-APPLE TREES}

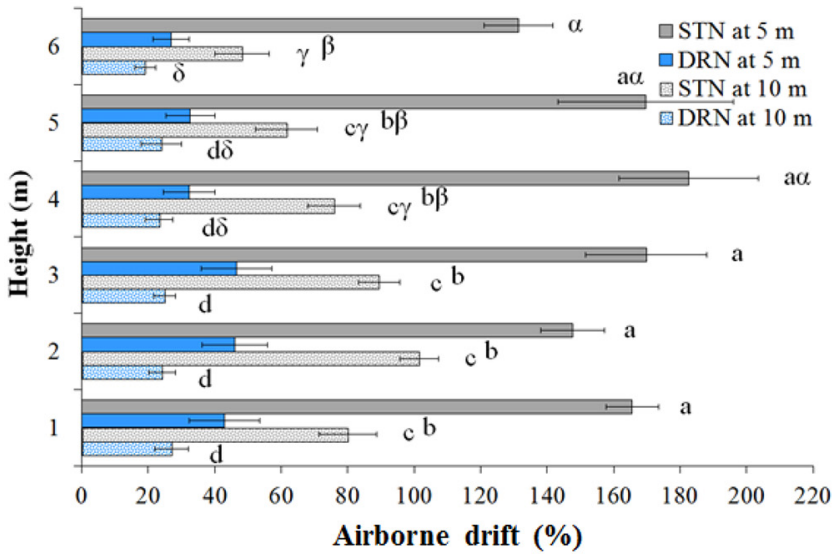

the fixed factor $\mathrm{B}$ (detection horizontal distance); $\alpha \beta_{i j}$ the effect of the interaction between the fixed factors $\mathrm{A}$ and $\mathrm{B}$; and $e_{i j l}$ the error term.

In both factorial analyses, Box-Cox transformations were applied to the data when necessary to meet the assumptions of homogeneity of variance (Bartlett test) and normality (Shapiro-Wilk test). The Tukey honest significant difference (HSD) test was used in each case as a pairwise multiple comparisons technique to search for specific differences. In all tests, a confidence level of $95 \%$ was considered. Open source RStudio software (version 1.2.1335) was used for data analysis.

2.5.1.2. Spray drift potential reduction. The spray drift recovery obtained in each ISO test was calculated according to the following expressions:

$C R_{V}=\sum_{k=1}^{6} V_{F(k)}$

$C R_{H}=\sum_{j=1}^{13} V_{F(j)}$

where $C R_{V}$ and $C R_{H}$ are the total airborne spray drift recovery (\%) and the total sedimenting spray drift recovery (\%), respectively; and $V_{F(k)}$ and $V_{F(j)}$ are the airborne spray drift at the vertical section of the collector line $k(\%)$ and the sedimenting spray drift at the horizontal collector $j$ (\%), respectively. Airborne spray drift was computed on the basis of the spray drift deposits to the corresponding sections of the collectors, following the procedure detailed in Torrent et al. (2017).

In each of the tests, the calculation of the spray drift potential reduction (DPR) was made from the spray drift recovery values of the
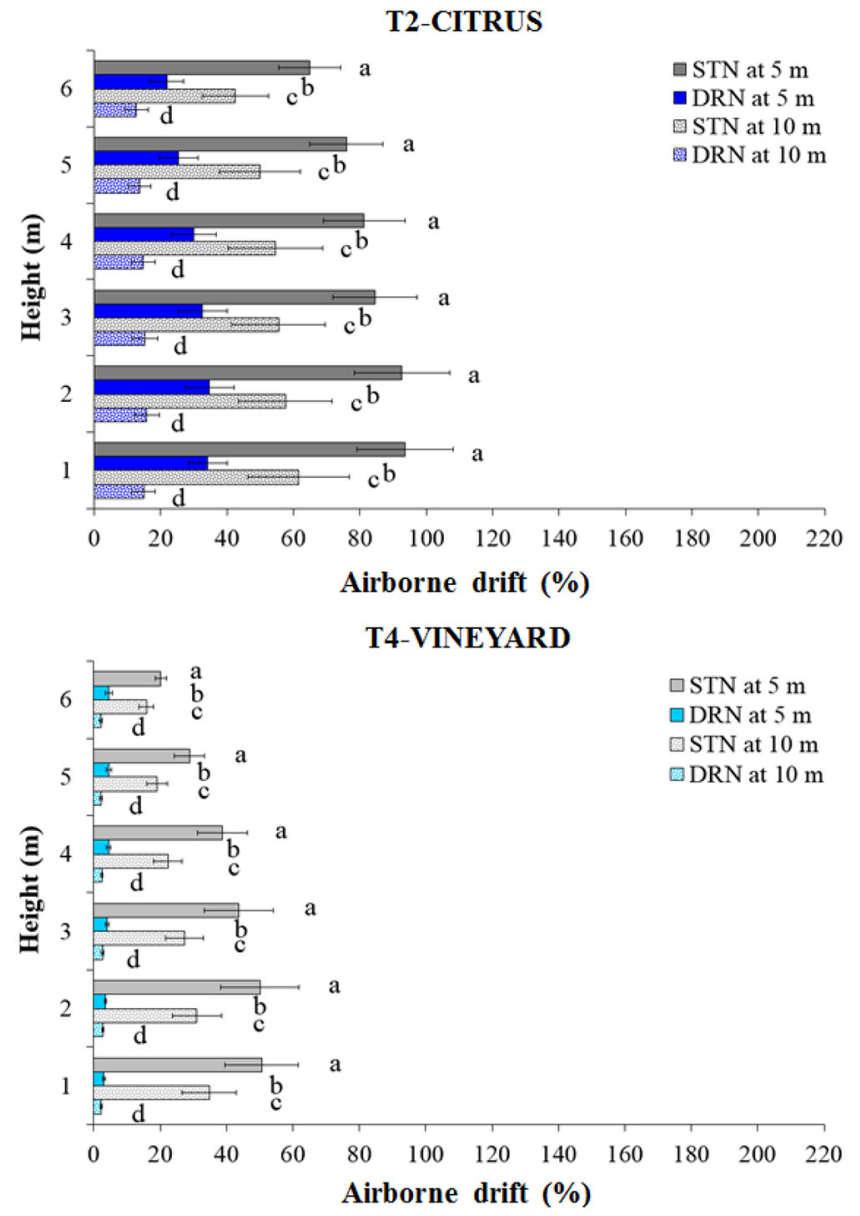

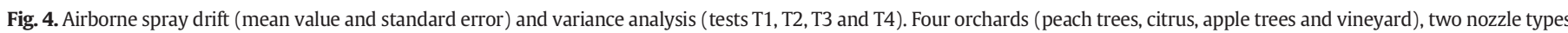
(STN and DRN), two distances ( $5 \mathrm{~m}$ and $10 \mathrm{~m}$ ), and six heights (1-6 m) were tested. 
candidate nozzle and the reference nozzle, applying the following expression:

$D P R=\left(1-\left(C R_{C} / C R_{R}\right)\right) \cdot 100$

where $C R_{C}$ is the spray drift potential of the candidate nozzle (\%) and $C R_{R}$ is the spray drift potential of the reference nozzle (\%).

2.5.1.3. Regression functions for sedimenting spray drift. A total of eight continuous functions of the variable sedimenting spray drift were determined as a function of distance, corresponding to the combination of each type of crop (peach, citrus, apple and grape) and nozzle (STN and DRN). For this, the regression functions were found from the mean values of the set of repetitions (tests T1, T2, T3 and T4). The regression function that presented a better fit in all cases was exponential, according to the following expression:

$y=a * \operatorname{Exp}^{(-b \cdot x)}$

where $y$ represents the deposition of the sedimenting spray drift (\%); $a$ the scale factor; $b$ the growth rate; and $x$ the distance $(\mathrm{m})$.

Two additional regression functions were obtained for each kind of nozzle considering the set of depositions obtained in all crops, with the exception of apple, since its growth stage (leaf fall) was different from the rest of the crops. For all functions, the values corresponding to the root mean square error (RMSE) and the coefficient of determination $\left(R^{2}\right)$ were obtained. Also, constant variance and autocorrelation diagnosis were checked on the linearized model to meet the corresponding assumptions. Finally, from the regression functions obtained, the buffer zones
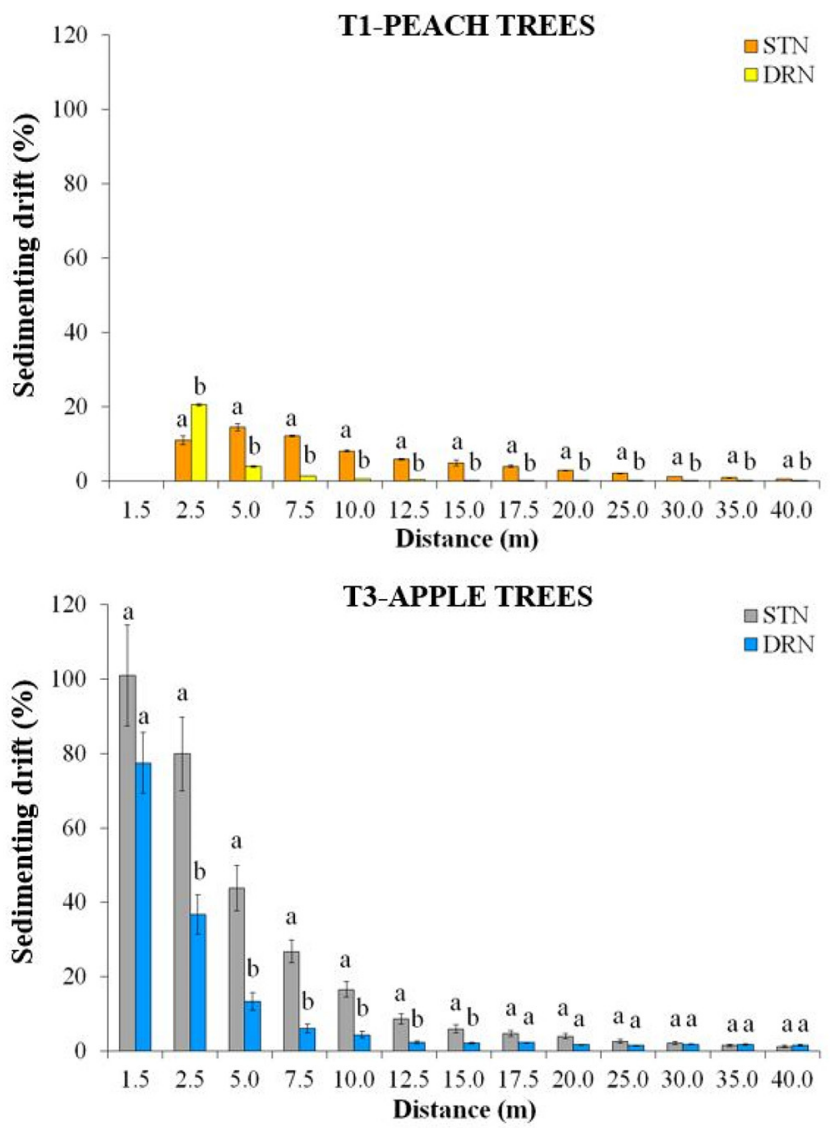

corresponding to the $10 \%, 5 \%$ and $1 \%$ spray drift values were determined based on the total collected, for each crop and nozzle type (STN and DRN).

\subsubsection{LiDAR spray drift tests}

Post-processing of the data obtained with the LiDAR system was carried out through the numerical computing software Matlab (R2018a, MathWorks Inc., Nastik, Massachusetts, USA). The resulting LiDAR signal was background and range-corrected. To determine the background signal, the measurements taken during the first $30 \mathrm{~s}$ of each scan sequence were considered. The range correction took into account that the LiDAR signal decreases with the square of the distance (Wandinger, 2005). From the corrected signal, the integrated LiDAR signal $\left(S_{\text {Int }}\right)$, normalized by the sprayed volume and by the laser pulse repetition rate, was calculated following the procedure described by Gregorio et al. (2019). The calculation of the reduction potential of the nozzles using the LiDAR ( $\left.D P R_{\text {lidar }}\right)$ system was performed according to the following expression:

$D P R_{\text {lidar }}=\left(1-\frac{S_{\text {Int }, C}}{S_{\text {Int }, R}}\right) \cdot 100$

where $S_{\text {Int,C }}$ and $S_{\text {Int, } R}$ are the integrated LiDAR signal of the candidate nozzle and the reference nozzle, respectively.

As in the case of the ISO tests, an ANOVA for a particular sprayer (Tifone) was carried out based on the data of the integrated LiDAR signal, with the aim of assessing the effect of nozzle type. In this case, it was necessary to perform a signal transformation (inverse function) to meet the assumptions of data normality and homoscedasticity. Subsequently, a two-way ANOVA was conducted to assess
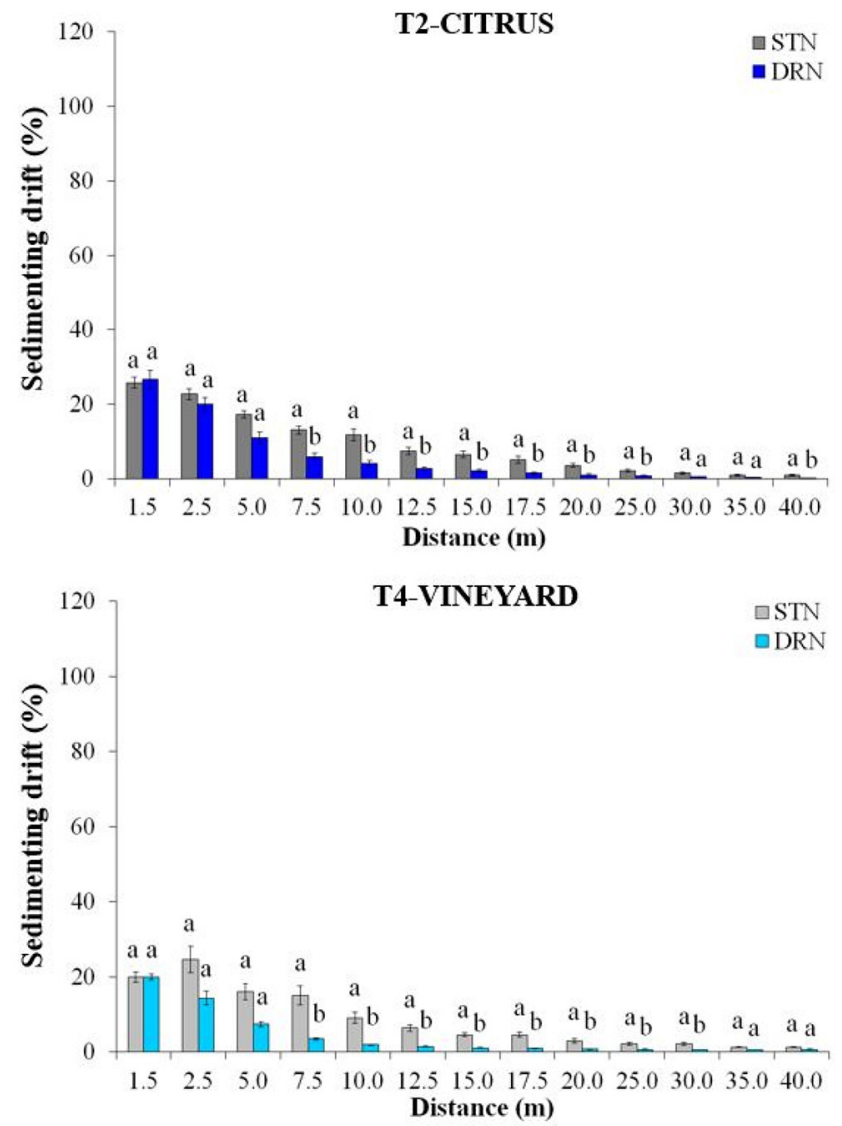

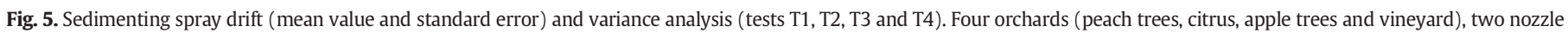
types (STN and DRN), and thirteen distances (1.5-40 m) were tested. 


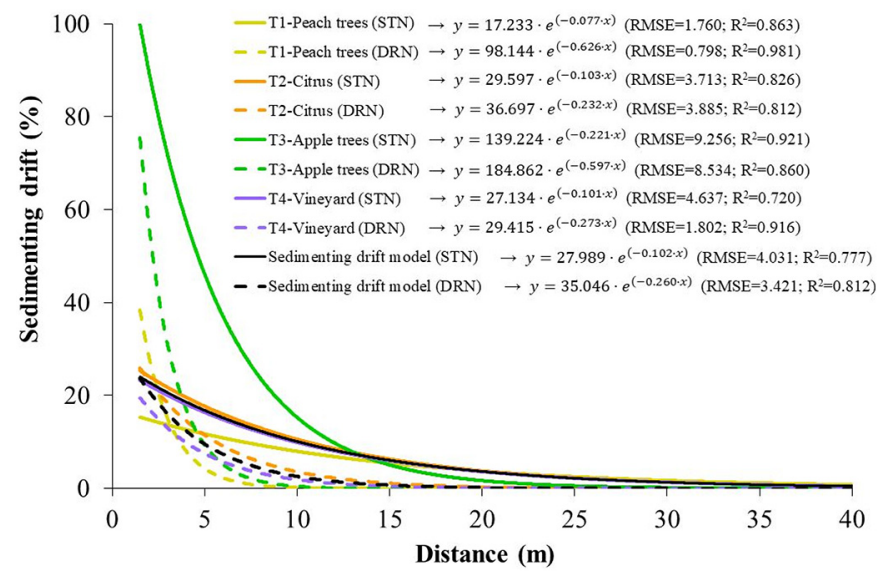

Fig. 6. Fitted exponential functions of the sedimenting spray drift for the different tested orchards and nozzle types.

the effect of nozzle (STN and DRN) and sprayer (Tifone and Munckhof) on the spray drift detected by the LiDAR system. To meet the assumptions in this case, square root transformation of the LiDAR signal was necessary.

\section{Results}

\subsection{Spray drift assessment based on ISO methodology}

The average values of the airborne spray drift measured at distances of 5 and $10 \mathrm{~m}$, up to a height of $6 \mathrm{~m}$, for the four crops (tests T1, T2, T3
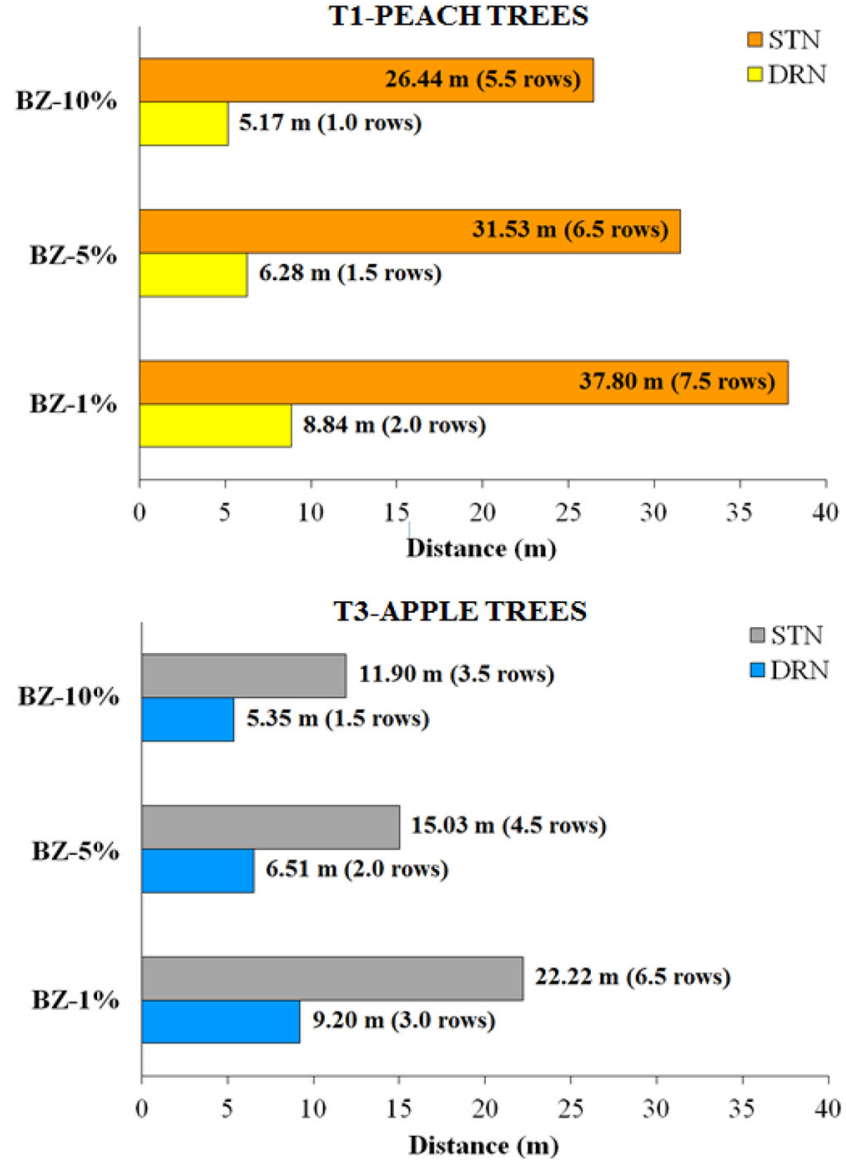

and T4) and the two types of nozzle (STN and DRN) tested, are represented in the bar graphs of Fig. 4 with their respective standard error. The deposits of spray drift values at $6 \mathrm{~m}$ were higher than the acceptable level specified in the ISO 22866:2005, because the deposits on this height related to the total spray drift collected were greater than the $10 \%$. On the other hand, the high deposits around or upper the $100 \%$ were probably due to the air turbulences, so some droplets were deposited on both sides and on the back part of vertical collectors. In the statistical analysis, the significance of the main effects (nozzle type, height and distance) and the existence of any interaction between them were studied. The results showed significant differences between the nozzle type in all crops. In contrast, the height effect was only significant for peach trees (specifically at the height of $1 \mathrm{~m}$ ) and apple trees (height of $6 \mathrm{~m}$ ). With respect to the distance effect, this was significant for all crops and nozzle types except for DRN in peach trees.

In Fig. 5, the mean sedimenting spray drift values are shown for each sampled distance between 1.5 and $40 \mathrm{~m}$ (between 2.5 and $40 \mathrm{~m}$ for peach trees), for the two types of nozzle and the four crops considered in this work. Being significant the interaction nozzle-distance, Fig. 5 shows the spray drift deposit variation for both nozzles (STN and DRN) as we move away from the source of drift. With the exception of peach trees, differences between nozzles were only significant for certain distances, in general, for those closest to the source of the drift. In the case of peach trees, there are significant differences between the two nozzle types (STN and DRN) at all distances, with the STN values higher than those of the DRN, except at the distance of $2.5 \mathrm{~m}$. For the rest of the crops, significant differences were found at the following distances: citrus (7.5-25 $\mathrm{m}$ and $40 \mathrm{~m}$ ), apple trees (2.5-15 m) and vineyard (7.5-30 m). For both nozzle types and in all crops, a clear decreasing trend in sedimenting
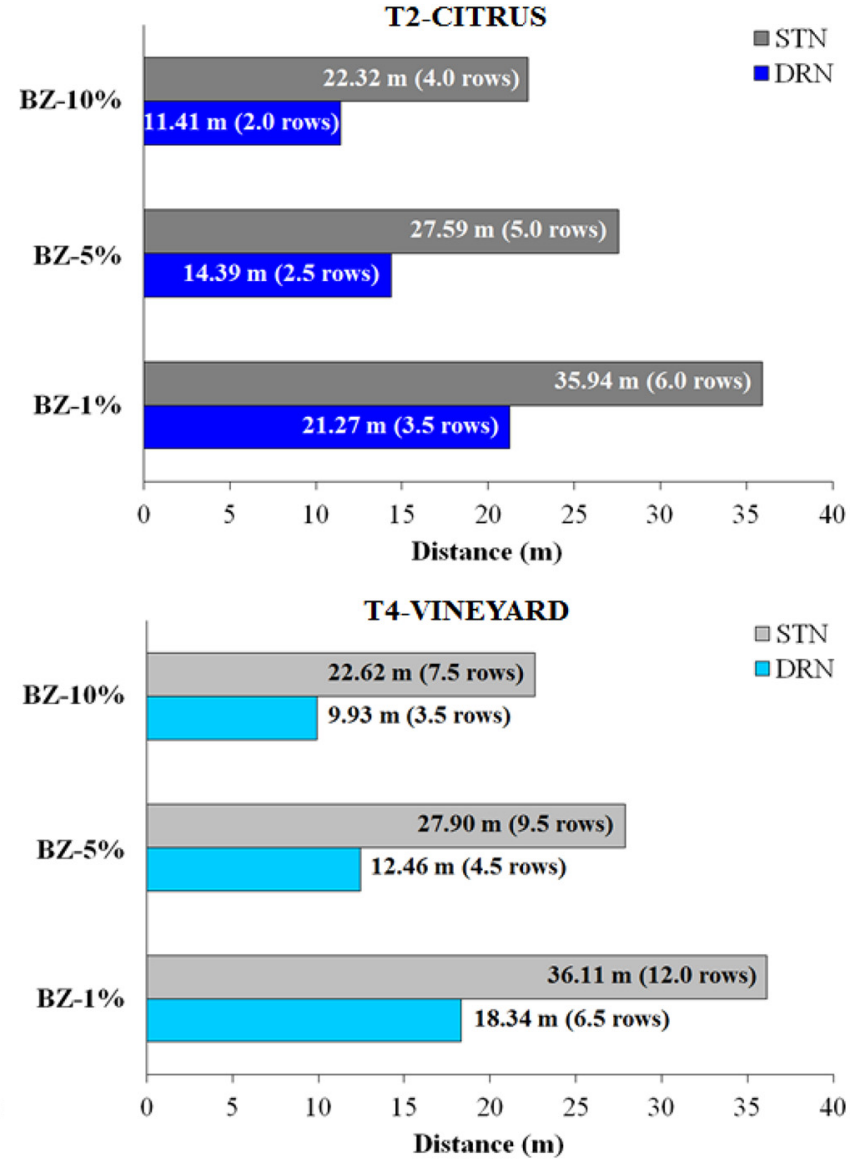

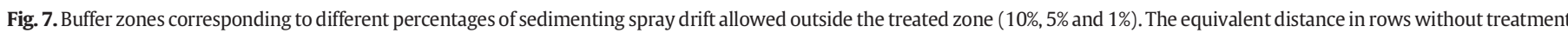
is shown in brackets. 
Table 4

DPR values (\%) for STN and DRN nozzle type comparisons (tests T1, T2, T3 and T4).

\begin{tabular}{llrrrccc}
\hline Test & Nozzle & $\begin{array}{c}\mathrm{CR}_{\mathrm{V}(5} \\
\mathrm{m})\end{array}$ & $\begin{array}{c}\mathrm{CR}_{\mathrm{V}(10} \\
\mathrm{m})\end{array}$ & $\begin{array}{c}\mathrm{CR}_{\mathrm{H}} \\
(\%)\end{array}$ & $\begin{array}{c}\mathrm{DPR}_{\mathrm{V}} \\
(\% \mathrm{~m})\end{array}$ & $\begin{array}{c}\mathrm{DPR}_{\mathrm{V}} \\
(10 \mathrm{~m}) \\
(\%)\end{array}$ & $\begin{array}{c}\mathrm{DPR}_{\mathrm{H}} \\
(\%)\end{array}$ \\
\hline \multirow{2}{*}{$\mathrm{T} 1$} & STN-O & 6.96 & 3.70 & 13.27 & - & - & - \\
& DRN-Y & 0.39 & 0.33 & 4.08 & 94.42 & 91.20 & 69.28 \\
$\mathrm{~T} 2$ & STN-G1 & 24.12 & 15.78 & 12.66 & - & - & - \\
& DRN-B1 & 8.73 & 4.60 & 7.63 & 63.82 & 70.84 & 39.75 \\
$\mathrm{~T} 3$ & STN-G2 & 22.16 & 10.23 & 24.07 & - & - & - \\
& DRN-B2 & 5.18 & 2.93 & 8.85 & 76.61 & 71.38 & 63.26 \\
$\mathrm{~T} 4$ & STN-G3 & 10.57 & 7.01 & 11.09 & - & - & - \\
& DRN-B3 & 1.17 & 0.70 & 4.52 & 88.95 & 90.00 & 59.27 \\
\hline
\end{tabular}

spray drift is observed as the distance increases up to $15 \mathrm{~m}$. Above this distance, it can be seen how spray drift reduction is practically negligible since it takes very low values. The higher sedimenting spray drift values in the first $7.5 \mathrm{~m}$ in the case of apple trees compared to other crops should also be noted.

The exponential functions fitted from the sedimenting spray drift values in each of the tests and for both nozzle types are presented in Fig. 6. In all cases a good fit is observed, with $\mathrm{R}^{2}$ values above 0.7 . Another aspect to highlight is that the functions that estimate the deposition of the DRN have a scale factor (a) greater than that of the STN, as well as a decrease rate (b) between two and eight times higher. The highest rate of decline corresponded to peach trees for the DRN nozzle type, followed by the apple trees-DRN, vineyard-DRN and citrus-DRN combinations.

Generic sedimenting spray drift curves for both nozzle types (STN and DRN) were also generated from the measurements obtained in three of the four crops (peach, citrus and grape). This was due to the major difference between the sedimenting spray drift values obtained in apple compared to the other crops.

The buffer zones were determined on the basis of the fitted exponential functions. These were found by establishing, for each nozzle in each crop, the following maximum percentages of sedimenting spray drift that are allowed outside the treatment area: $10 \%, 5 \%$ and $1 \%$. As can be seen in Fig. 7, the distances of the buffer zones for the DRN are reduced by about $50 \%$ in relation to the STN for citrus, apple trees and vineyard. In the case of peach trees, the reduction of the buffer zone achieved by the DRN was $>75 \%$. Equivalently, the buffer zone distances are also presented in terms of the number of rows that should be left untreated to prevent spray drift from reaching non-target areas (see values in brackets in Fig. 7), without considering the filtering capacity of the outside tree rows which could contribute to reduce the spray drift. The crops in which the longest buffer zones were obtained were

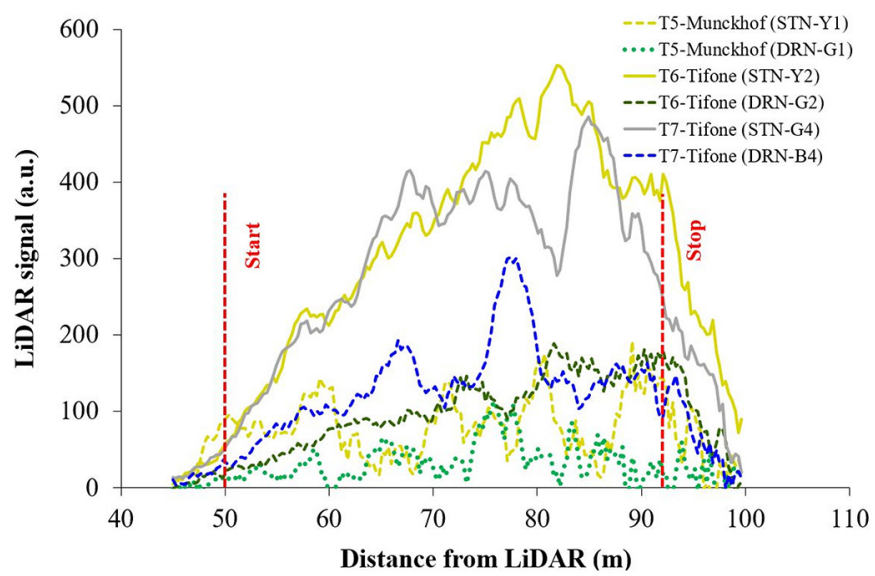

Fig. 8. Nozzle type comparison (STN vs. DRN) based on range profile of LiDAR returns. The LiDAR signal was normalized by the total sprayed volume.
Table 5

LiDAR-based DPR values (\%) for nozzle and sprayer type comparison (tests T5, T6 and T7).

\begin{tabular}{|c|c|c|c|c|c|}
\hline \multirow{2}{*}{ Test } & \multirow{2}{*}{ Sprayer } & \multicolumn{2}{|c|}{ Nozzle } & \multirow{2}{*}{$\begin{array}{l}\text { Pressure } \\
(\mathrm{kPa})\end{array}$} & \multirow{2}{*}{$\begin{array}{l}\mathrm{DPR}_{\text {lidar }} \\
\quad(\%)\end{array}$} \\
\hline & & Model & Type & & \\
\hline \multirow[b]{2}{*}{ T5 } & \multirow{2}{*}{$\begin{array}{c}\text { Munckhof VariMAS } \\
1\end{array}$} & ATR 80 Yellow & HC-STN & & - \\
\hline & & $\begin{array}{l}\text { TVI } 80015 \\
\text { Green }\end{array}$ & HC-DRN & 500 & 70.41 \\
\hline \multirow{3}{*}{ T6 } & \multirow{4}{*}{ Tifone 2000} & ATR 80 Yellow & HC-STN & 1600 & - \\
\hline & & TVI 80015 & HC-DRN & 1400 & 68.46 \\
\hline & & Green & & & \\
\hline $\mathrm{T} 7$ & & $\begin{array}{l}\text { ATR } 80 \text { Grey } \\
\text { TVI } 8003 \text { Blue }\end{array}$ & $\begin{array}{l}\text { HC-STN } \\
\text { HC-DRN }\end{array}$ & 500 & $\begin{array}{c}- \\
55.38\end{array}$ \\
\hline
\end{tabular}

HC-STN: Hollow-cone standard nozzle; HC-DRN: Hollow-cone spray drift reduction nozzle.

peach when SNTs are used and citrus when species are compared using DRN.

Table 4 shows the DPR values of the DRN nozzles compared to the STN, corresponding to airborne spray drift at $5 \mathrm{~m}$ and $10 \mathrm{~m}\left(D P R_{V(5 \mathrm{~m})}\right.$ and $\left.D P R_{V(10 m)}\right)$ and sedimenting spray drift $\left(D P R_{H}\right)$. The greatest spray drift reductions were obtained with the DRN nozzles in the T1 test (peach trees), followed by the T4 test (vineyard), the T3 test (apple trees) and the T2 test (citrus), with the exception of the $D P R_{H}$ of the T4 test which was slightly lower than that of the T3 test. The values of $D P R_{V(5 m)}$ and $D P R_{V(10 m)}$ were similar in all the tests performed. On the other hand, the $D P R_{H}$ values were lower than those for $D P R_{V}$ in all the crops evaluated.

\subsection{Spray drift assessment based on LiDAR measurements}

The results corresponding to the $\mathrm{T} 5, \mathrm{~T} 6$ and $\mathrm{T} 7$ tests, in which the spray drift was evaluated using a LiDAR system, are presented below. Fig. 8 shows the range profile of the LiDAR signal corresponding to two different sprayers (Munckhof VariMAS 1 and Tifone 2000), with two nozzle types (STN and DRN). As expected, the DRN presented much lower signal values compared to the STN. The configurations that presented the highest signal values were the STN (Y2 and G4) with the Tifone sprayer, while the Munckhof configuration with the DRN-G1 generated the lowest.

Table 5 shows the DPR values obtained from the integrated LiDAR signals $\left(S_{I n t}\right)$. It is observed that, regardless of the sprayer used, all DRN reduction values are $>50 \%$ compared to the respective STN values. It is also observed that, when comparing the ATR 80 Yellow and TVI 80015 Green nozzles, the DPR values are similar for both sprayers.

In addition, a statistical analysis was carried out based on the $S_{\text {Int }}$ values to determine the effect of nozzle and sprayer. The results showed significant differences between the nozzles tested (STN and DRN) in both sprayers, with the DRN obtaining the smallest signal. There were also significant differences between sprayers, with the highest LiDAR signals obtained for the Tifone sprayer regardless of nozzle type.

In Fig. 9, DPR values are presented by comparing STN and DRN nozzles (ATR 80 Grey and TVI 8003 Blue at 1.0 MPa) using different methods of evaluation. These values include the results obtained by Torrent et al. (2019) using the PDPA $\left(D_{V 50}, V_{100}\right.$ and $\left.V_{200}\right)$ and wind tunnel $\left(W T_{H}\right.$ and $\left.W T_{V}\right)$, with the LiDAR system (Gregorio et al. (2019) under laboratory and field conditions $\left(S_{L(L a b)}\right.$ and $\left.S_{L(\text { Field })}\right)$ and those corresponding to the T3 test (apple trees) of this work $\left(F_{H}, F_{V(5 m)}\right.$ and $F_{V}$ $(10 \mathrm{~m})$ ). It can be seen how the DPR values obtained with each of the different methods are $>50 \%$, with the highest DPR values obtained with the parameters $V_{100}(98.97 \%)$ and $V_{200}(96.38 \%)$ and the lowest with $S_{L(\text { Field })}$ (57.20\%) and $W T_{H}(58.50 \%)$. In addition, a statistical analysis was carried out to study whether there were significant differences between the different methodologies. From the results of this analysis, the parameters studied can be grouped as follows: group $\mathrm{A}\left(D_{V 50}, W T_{V}, F_{V(5 m)}\right.$ and $F_{V}$ 


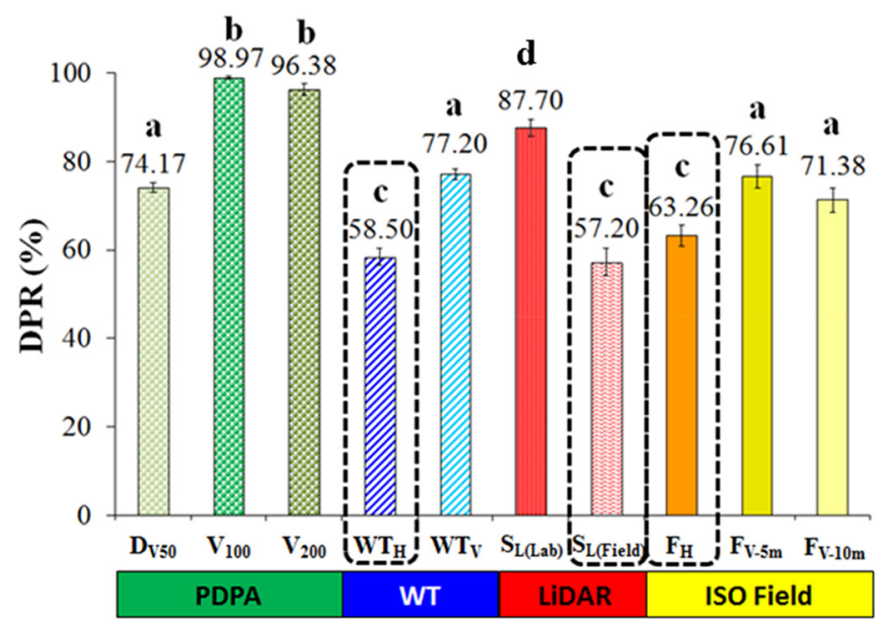

Fig. 9. Indirect and direct methods comparison for the hollow-cone nozzles ATR 80 Grey and TVI 8003 Blue in apple trees application. The DPR values (mean \pm SE) are shown. Different letters indicate statistically significant differences (Tukey's HSD test, $p<0.05$ ). (For interpretation of the references to colour in this figure legend, the reader is referred to the web version of this article.)

(10m)), group B $\left(V_{100}\right.$ and $\left.V_{200}\right)$, group $C\left(W T_{H}, S_{L(\text { Field })}\right.$ and $\left.F_{H}\right)$ and group $\mathrm{D}\left(S_{L(L a b)}\right)$.

\section{Discussion}

In the spray drift evaluation tests for the 4 crops studied (peach, citrus, apple and grape), both airborne and sedimenting spray drift were evaluated. In all cases, the airborne spray drift generated by the STN was significantly greater than that generated by the DRN, with the latter showing a clear reduction effect regardless of crop type or distance to the treatment area. In addition, the airborne spray drift evaluated at a distance of $5 \mathrm{~m}$ from the treatment area was much greater than at $10 \mathrm{~m}$, as expected. The results confirmed that the type of nozzle used is one of the most influential and effective variable for spray drift control. Also, it should be noted that the airborne drift values were much higher than those for sedimenting spray drift.

With respect to sedimenting spray drift, a clear buffer zone for each nozzle type (STN and DRN) was obtained, with a significant reduction of sedimenting spray drift obtained at close distances $(2.5-7.5 \mathrm{~m}$ ) and remote distances (15-30 m). Nonetheless, most of the sedimenting spray drift was concentrated in the first $10-15 \mathrm{~m}$, distances which should be taken into account when sizing buffer zones to prevent the contamination of nearby water bodies or adjacent crops.

The high airborne and sedimenting spray drift values obtained in apple can be attributed to the growth stage ( $\mathrm{BBCH} 93$, beginning of leaf fall) of the crop itself at the time the spray drift tests were made and to the high value of the air flow rate. Due to the fall of the leaves, the percentage of gaps was higher than in the rest of the crops, offering less resistance to the passage of the droplets. It is clear then, that crop growth stage is a very important variable in relation to spray drift, and should be taken into account when establishing spray drift models. Indeed, in the biexponential spray drift model established by Holterman et al. (2017), the BBCH growth stage variable was in fact taken into account.

The functions that best fitted the sedimenting spray drift data were those of the exponential type. The fitted functions of the DRN presented scale factors and decrease rates higher than those of the STN. This is attributable to the fact that the DRN nozzles had higher sedimenting spray drift at close distances and a higher reduction effect as distance increases. Of the set of crops tested in full leaf stages, special attention should be paid to citrus since, due to their globular shape and the high volumes of spray liquid that are applied to reach all parts of the canopy, more airborne spray drift is generated than with the other crops. In this line, the German model (Ganzelmeier et al., 1995; Rautmann et al., 2001) shows a strong reduction of spray drift in the first $5 \mathrm{~m}$, as do the spray drift functions presented in this work. Despite this, the German model overestimates the sedimenting spray drift generated for the STN in citrus in the first $2.5 \mathrm{~m}$ and, above this distance, underestimates it.

Using DRN instead of STN allows over a 50\% reduction in the distance of the buffer zones. In this way, production losses due to nontreatment could be avoided as, in small plots, the solution which is proposed is not to treat instead of leaving an uncultivated area. It should also be noted that the functions obtained for apple start from much higher scale factors than the other crops as, in this case, very high deposition values were obtained in the first $7.5 \mathrm{~m}$ compared to the other crops (Fig. 5).

With respect to DPR, special note should be made of the high reduction capacity of DRN compared to STN, especially for airborne spray drift. This confirms how nozzle type is one of the best DRTs for practical purposes for any of the 3D crops tested in the southern part of Europe, since it does not require the implementation of any changes to the plot and its cost is very low.

The new methodology developed to evaluate spray drift in real field conditions using the LiDAR system allowed real-time measurement of the spray drift cloud generated during the treatment, with a high spatio-temporal resolution. This was achieved by scanning the spray drift cloud in a vertical plane with the LiDAR system, which is able to differentiate the spray drift produced by different configurations of the spray-nozzle assembly. In addition to facilitating spray drift evaluation logistics and operations, this new methodology can be adapted to any type of plot and has a very short execution time since it does not require a free strip of land adjacent to the plot to perform measurements. In this way, numerous tests can be carried out, substantially reducing the staff, time and space requirements when following the ISO 22866:2005 methodology.

As previously mentioned, one of the main advantages of the LiDAR system is the evaluation of spray drift in real time (Fig. 8), along with its ability to determine the spray drift profile as a function of distance. This allows the detection of fluctuations in spray drift generated during the application, which are mainly due to variations in the percentage of gaps present in the canopy or to weather conditions (wind speed and direction). According to the results of Table 5, for practical treatment purposes (sprayer calibrated according to the crop), the DRN (TVI 80015 Green) presented a similar reduction regardless of the type of machine used (T5: 70.41\%; T6: 68.46\%); therefore, in this case, the reduction due to sprayer and nozzle type is a cumulative effect. Comparing the DPR results obtained in the T5 and T7 tests for DRN (TVI 80015 Green and TVI 8003 Blue) at the pressure of $500 \mathrm{kPa}$ (Table 5) with their equivalents in the PDPA (DPR $R_{V 100}: 99.34 \%$ and $\left.98.54 \%\right)$ and wind tunnel $\left(D P R_{H}: 88.24 \%\right.$ and $58.50 \%$; $D P R_{V}: 86.86 \%$ and $\left.77.20 \%\right)$ (Torrent et al., 2019) tests, some similarity can be observed with the wind tunnel (WT) results for sedimenting spray drift, with the latter higher as they were carried out in a confined space and under controlled environmental conditions.

In the comparison between the DPR results obtained in the T3 test with the ATR 80 Grey and TVI 8003 Blue nozzles at $1 \mathrm{MPa}$ using the ISO $22866: 2005$ methodology $\left(F_{H}=63.26 \%, F_{V(5 m)}=\right.$ $76.61 \%$ and $\left.F_{V(10 m)}=71.38 \%\right)$ with those obtained with the indirect methods (PDPA and WT) and the LiDAR system, a very good correspondence was obtained between the $F_{H}$ parameter and the results obtained with the LiDAR system in field conditions $\left(S_{L}\right.$ $\left.{ }_{(\text {Field })}=57.20 \%\right)$ and the WT sedimenting spray drift parameter $\left(W T_{H}=58.50 \%\right)$. In contrast, the values of the $F_{V(5 m)}$ and $F_{V(10 m)}$ parameters were similar to those obtained with the PDPA $\left(D_{V 50}=74.17 \%\right)$ and the WT airborne spray drift parameter $\left(W T_{V}=77.20 \%\right)$. 


\section{Conclusions}

In this work, spray drift was evaluated under field conditions using the ISO 22866:2005 methodology for four 3D crops (peach, citrus, apple and grape) in plots in the EU Southern Zone, comparing STN and DRN nozzles. In all the crops tested, the DRN proved to be an effective and practical technique for the reduction of airborne and sedimenting spray drift.

Subsequently, an approach to an initial 3D crop spray drift model was developed and adapted to the conditions of Southern Europe, for both nozzle types. Buffer zones were determined on the basis of these models. The crop growth stage variable was found to be an important factor in the generation of spray drift and must be taken into account when building the models.

Finally, a new methodology was defined and tested to evaluate spray drift in field conditions using a LiDAR system. This new methodology, based on scanning the spray drift cloud in the vertical plane, was found to be a practical and effective method for the characterization and determination of DPR in a variety of situations.

In future work, progress needs to be made in the generation of a robust model which can be used by the relevant authorities to determine buffer zone dimensions in 3D crops taking into account the main parameters of influence in spray drift. To achieve this result, additional tests will have to be carried out in different scenarios (crops and plots), configurations (sprayers, air assistance, nozzles and operating conditions) and weather conditions. The availability of a new LiDAR methodology for spray drift evaluation, with significant advantages in terms of monitoring and cost, will be crucial to carry out this broad experimental campaign.

\section{CRediT authorship contribution statement}

Xavier Torrent:Conceptualization, Methodology, Software, Investigation, Formal analysis, Data curation, Writing - original draft, Writing - review \& editing.Eduard Gregorio:Conceptualization, Methodology, Software, Investigation, Formal analysis, Writing - original draft, Writing - review \& editing, Supervision.Joan R. Rosell-Polo:Conceptualization, Methodology, Investigation, Writing - review \& editing, Supervision, Funding acquisition.Jaume Arnó:Software, Formal analysis, Writing original draft, Writing - review \& editing.Miquel Peris:Investigation, Writing - review \& editing.Jan C. van de Zande:Investigation, Writing review \& editing.Santiago Planas:Conceptualization, Methodology, Investigation, Writing - review \& editing, Supervision.

\section{Declaration of competing interest}

The authors declare that they have no known competing financial interests or personal relationships that could have appeared to influence the work reported in this paper.

\section{Acknowledgements}

This work was partly funded by the Secretaria d'Universitats i Recerca del Departament d'Empresa i Coneixement de la Generalitat de Catalunya, the Spanish Ministry of Economy and Competitiveness and the European Regional Development Fund (ERDF) under grants 2017 SGR 646, AGL2007-66093-C04-03, AGL2010-22304-04-C03-03, and AGL2013-48297-C2-2-R. The authors also wish to thank Mr. Antonio Checa (Randex Iberica, S.L.) for giving us free Albuz nozzles for the spray tests. Universitat de Lleida is also thanked for Mr. X. Torrent's pre-doctoral fellowship.

\section{References}

Blanco, M.N., Fenske, R.A., Kasner, E.J., Yost, M.G., Seto, E., Austin, E., 2019. Real-time monitoring of spray drift from three different orchard sprayers. Chemosphere 222, 46-55. https://doi.org/10.1016/j.chemosphere.2019.01.092.
Bourodimos, G., Koutsiaras, M., Psiroukis, V., Balafoutis, A., Fountas, S., 2019. Development and field evaluation of a spray drift risk assessment tool for vineyard spraying application. Agriculture 9, 181. https://doi.org/10.3390/agriculture9080181.

Butler Ellis, M.C., Lane, A.G., O'Sullivan, C.M., Miller, P.C.H., Glass, C.R., 2010. Bystander exposure to pesticide spray drift: new data for model development and validation. Biosyst. Eng. 107, 162-168. https://doi.org/10.1016/j.biosystemseng.2010.05.017.

Butler Ellis, M.C., Kennedy, M.C., Kuster, C.J., Alanis, R., Tuck, C.R., 2018. Improvements in modelling bystander and resident exposure to pesticide spray drift: investigation into new approaches for characterizing the collection efficiency of the human body. Ann. Work Expos. Health 62 (5), 622-632. https://doi.org/10.1093/annweh/wxy017.

Carlsen, S.C.K., Spliid, N.H., Svensmark, B., 2006. Drift of 10 herbicides after tractor spray application. 2. Primary drift (droplet drift). Chemosphere 64, 778-786. https://doi. org/10.1016/j.chemosphere.2005.10.060.

Castro-Tanzi, S., Padilla, L., Brausch, J., Winchell, M., Hanzas, J., 2018. Estimating appropriate buffer distances to mitigate environmental risk of spray drift using field data and computer automation. Abstracts of Papers of the $256^{\text {th }}$ National Meeting and Exposition of the American-Chemical-Society (ACS), Boston, MA.

Cunha, J.P., Chueca, P., Garcerá, C., Moltó, E., 2012. Risk assessment of pesticide spray drift from citrus application with air-blast sprayers in Spain. Crop Prot. 42, 116-123. https://doi.org/10.1016/j.cropro.2012.06.001.

Da Silva, A., Sinfort, C., Tinet, C., Pierrot, D., Huberson, S., 2006. A Lagrangian model for spray behaviour within vine canopies. Aerosol Sci. 37, 658-674. https://doi.org/ 10.1016/j.jaerosci.2005.05.016.

Damalas, Christos A., 2015. Chapter 15. Pesticide drift: seeking reliable environmental indicators of exposure assessment. In: Armon, R.H., Hanninen, O. (Eds.), Environmental Indicators. Springer Publishing Company, the Netherlands, pp. 251-264.

De Schampheleire, M., Spanoghe, P., Brusselman, E., Sonck, S., 2007. Risk assessment of pesticide spray drift damage in Belgium. Crop Prot. 26, 602-611. https://doi.org/ 10.1016/j.cropro.2006.05.013.

Derksen, R.C., Zhu, H., Fox, R.D., Brazee, R.D., Krause, C.R., 2007. Coverage and drift produced by air induction and conventional hydraulic nozzles used for orchard applications. Trans. ASABE 50 (5), 1493-1501.

Duga, A.T., Delele, M.A., Ruysen, K., Dekeyser, D., Nuyttens, D., Bylemans, D., Nicolai, B.M., Verboven, P., 2017. Development and validation of 3D CFD model of drift and its application to air-assisted orchard sprayers. Biosyst. Eng. 154, 62-75. https://doi.org/ 10.1016/j.biosystemseng.2016.10.010.

EPA - United States Environmental Protection Agency, 2018. Introduction to pesticide drift [WWW document]. URL. https://www.epa.gov/reducing-pesticide-drift/introduction- pesticide-drift,

EPPO (European and Mediterranean Plant Protection Organization), 2003. Environmental risk assessment scheme for plant protection products. Chapter 9: non-target terrestrial arthropods. Bulletin EPPO 33, 99-101.

European Union, 2009. Directive 2009/128/EC of the European Parliament and of the Council of 21 October 2009 establishing a framework for community action to achieve the sustainable use of pesticides. Off. J. Eur. Union 309, 71-86 (of 24/11/2009).

Eurostat, 2016. Eurostat-Database [online].Available in. https://ec.europa.eu/eurostat/ data/database (Access date: September 10th 2019).

Ganzelmeier, H., Rautmann, D., Spangenberg, R., Streloke, M., Herrmann, M., Wenzelburger, H.J., 1995. Studies on the Spray Drift of Plant Protection Products. Blackwell Wissenschafts, Verlag GmbH, Berlin.

Garcerá, C., Moltó, E., Chueca, P., 2017. Spray pesticide applications in Mediterranean citrus orchards: canopy deposition and off-target losses. Sci. Total Environ. 599-600, 1344-1362. https://doi.org/10.1016/j.scitotenv.2017.05.029.

Gil, Y., Sinfort, C., Brunet, Y., Polveche, V., Bonicelli, B., 2007. Atmospheric loss of pesticides above an artificial vineyard during air-assisted spraying. Atmos. Environ. 41, 2945-2957. https://doi.org/10.1016/j.atmosenv.2006.12.019.

Gil, E., Llorens, J., Llop, J., Fàbregas, X., Gallart, M., 2013. Use of a terrestrial LiDAR sensor for drift detection in vineyard spraying. Sensors 13 (1), 516-534. https://doi.org/ 10.3390/s130100516.

Gregorio, E., Rosell-Polo, J.R., Sanz, R., Rocadenbosch, F., Solanelles, F., Garcerà, C., Chueca, P., Arnó, J., del Moral, I., Masip, J., Camp, F., Viana, R., Escolà, A., Gràcia, F., Planas, S., Moltó, E., 2014. LIDAR as an alternative to passive collectors to measure pesticide spray drift. Atmos. Environ. 82, 83-93. https://doi.org/10.1016/j. atmosenv.2013.09.028.

Gregorio, E., Rocadenbosch, F., Sanz, R., Rosell-Polo, J.R., 2015. Eye-safe lidar system for pesticide spray drift measurement. Sensors (Switzerland) 15, 3650-3670. https:// doi.org/10.3390/s150203650.

Gregorio, E., Torrent, X., Planas, S., Solanelles, F., Sanz, R., Rocadenbosch, F., Masip, J., Ribes-Dasi, M., Rosell-Polo, J.R., 2016. Measurement of spray drift with a specifically designed lidar system. Sensors 16 (4), 499. https://doi.org/10.3390/s16040499.

Gregorio, E., Torrent, X., Planas, S., Rosell-Polo, J.R., 2019. Assessment of spray drift potential reduction for hollow-cone nozzles: part 2. LiDAR-technique. Sci. Total Environ. 687, 967-977. https://doi.org/10.1016/j.scitotenv.2019.06.151.

Hiscox, A.L., Miller, D.R., Nappo, C.J., Ross, J., 2006. Dispersion of fine spray from aerial applications in stable atmospheric conditions. Trans. ASABE 49 (5), 1513-1520.

Holterman, H.J., van de Zande, J.C., Huijsmans, J.F.M., Wenneker, M., 2017. An empirical model based on phenological growth stage for predicting pesticide spray drift in pome fruit orchards. Biosyst. Eng. 154, 46-61. https://doi.org/10.1016/j. biosystemseng.2016.08.016.

ISO 22866, 2005. Equipment for Crop Protection - Methods for Field Measurement of Spray Drift. International Organization for Standardization, Geneva, Switzerland.

Kasner, E.J., Fenske, R.A., Hoheisel, G.A., Galvin, K., Blanco, M.N., Seto, E.Y.W., 2018. Spray drift from conventional axial fan airblast sprayer in a modern orchard work environment. Ann. Work Expo. Health 62 (9), 1134-1146. https://doi.org/10.1093/annweh/ wxy082. 
Kira, O., Dubowski, Y., Linker, R., 2018. In-situ open path FTIR measurements of the vertical profile of spray drift from air-assisted sprayers. Biosyst. Eng. 169, 32-41. https:// doi.org/10.1016/j.biosystemseng.2018.01.010.

Lešnik, M., Stajnko, D., Vajs, S., 2015. Interactions between spray drift and sprayer travel speed in two different apple orchard training systems. Int. J. Environ. Sci. Technol. 12, 3017-3028. https://doi.org/10.1007/s13762-014-0724-7.

Muscutt, A.D., Harris, G.L., Bailey, S.W., Davies, B.D., 1993. Buffer zones to improve water quality: a review of their potential use in UK agriculture. Agric. Ecosyst.Environ. 45 (1-2), 59-77.

Nuyttens, D., Sonck, B., de Schampheleire, M., Steurbaut, W., Baetens, K., Verboven, P., Nicolaï, B., Ramon, H., 2005. Spray drift as affected by meteorological conditions. Commun. Agric. Appl. Biol. Sci. 70, 947-959.

Nuyttens, D., De Schampheleire, M., Verboven, P., Sonck, B., 2010. Comparison between indirect and direct spray drift assessment methods. Biosyst. Eng. 105, 2-12. https:// doi.org/10.1016/j.biosystemseng.2009.08.004.

Ramos, C., Carbonell, G., Baudín, García, Ma, J., Tarazona, J.V., 2000. Ecological risk assessment of pesticides in the Mediterranean region. The need for crop-specific scenarios. Sci. Total Environ. 247, 269-278.

Rautmann, D., Streloke, M., Winkler, R., 2001. New basic drift values in the authorisation procedure for plant protection products. In: Forster, R., Streloke, M. (Eds.), Workshop on Risk Assessment and Risk Mitigation Measures in the Context of the Authorisation of Plant Protection Products (WORMM). Mitt. Biol. Bundesanst. Land-Forstwirtsch, Berlin, pp. 133-141.

Richardson, B., Strand, T., Thistle, H.W., Hiscox, A., Kimberley, M.O., Schou, W.C., 2017. Influence of a young pinus radiata canopy on aerial spray drift. Trans. ASABE 60 (6), 1851-1861. https://doi.org/10.13031/trans.12497.

Salyani, M., Miller, D.R., Farooq, M., Sweeb, R.D., 2013. Effects of sprayer operating parameters on airborne drift from citrus air-carrier sprayers. Agric. Eng. Int. CIGR J. 15 (1), 27-36. www.cigrjournal.org.

Sanz, R., Llorens, J., Escolà, A., Arnó, J., Planas, S., Román, C., Rosell-Polo, J.R., 2018. LIDAR and non-LIDAR-based canopy parameters to estimate the leaf area in fruit trees and vineyard. Agric. For. Meteorol. 260-261, 229-239. https://doi.org/10.1016/j. agrformet.2018.06.017.
Sarigiannis, D.A., Kontoroupis, P., Solomou, E.S., Nikolaki, S., Karabelas, A.J., 2013. Inventory of pesticide emissions into the air in Europe. Atmos. Environ. 75, 6-14. https:// doi.org/10.1016/j.atmosenv.2013.04.003.

Sjerps, R.M.A., Kooij, P.J.F., Van Loon, A., Van Wezel, A.P., 2019. Occurrence of pesticides in Dutch drinking water sources. Chemosphere 235, 510-518. https://doi.org/10.1016/j. chemosphere.2019.06.207.

Stainier, C., Destain, M.F., Schiffers, B., Lebeu, F., 2006. Droplet size spectra and drift effect of two phenmedipham formulations and four adjuvants mixtures. Crop Prot. 25, 1238-1243. https://doi.org/10.1016/j.cropro.2006.03.006.

Torrent, X., Garcerá, C., Moltó, E., Chueca, P., Abad, R., Grafulla, C., Román, C., Planas, S. 2017. Comparison between standard and drift reducing nozzles for pesticide application in citrus: part I. effects on wind tunnel and field spray drift. Crop Prot. 96, 130-143. https://doi.org/10.1016/j.cropro.2017.02.001.

Torrent, X., Gregorio, E., Douzals, J.P., Tinet, C., Rosell-Polo, J.R., Planas, S., 2019. Assessment of spray drift potential reduction for hollow-cone nozzles: part 1. Classification using indirect methods. Sci. Total Environ. 692, 1322-1333. https://doi.org/10.1016/j. scitotenv.2019.06.121.

Van de Zande, J.C., Stallinga, H., Michielsen, J.M.G.P., van Velde, P., 2010. Effect of width of spray-free buffer zones, nozzle type and air assistance on spray drift. Asp. Appl. Biol.: Int. Adv. Pestic. Appl. 99, 255-263.

Wandinger, U., 2005. Introduction to Lidar. In: Weitkamp, C. (Ed.), Lidar. Range-Resolved Optical Remote Sensing of the Atmosphere. Springer-Verlag, pp. 1-18. https://doi org/10.1007/0-387-25101-4_1.

Wenneker, M., van de Zande, J.C., Michielsen, J.M.G.P., Stallinga, H., van Velde, P., 2016 Spray deposition and spray drift in orchard spraying by multiple row sprayers. International advances in pesticide application. Asp. Appl. Biol. 132, 137-144.

Wolters, A., Linnemann, V., van de Zande, J.C., Vereecken, H., 2008. Field experiment on spray drift: deposition and airborne drift during application to a winter wheat crop. Sci. Total Environ. 405, 269-277. https://doi.org/10.1016/j.scitotenv.2008.06.060. 